\title{
Could Nanotechnology Help to End the Fight Against COVID-19? Review of Current Findings, Challenges and Future Perspectives
}

\author{
Ashagrachew Tewabe Yayehrad (iD) 1,2 \\ Ebrahim Abdela Siraj (iD ${ }^{1,2}$ \\ Gebremariam Birhanu \\ Wondie (ID)' \\ Atlaw Abate Alemie (iD) 1,3 \\ Manaye Tamrie Derseh (iD) 1,4 \\ Abyou Seyfu Ambaye (iD ${ }^{4}$
}

'Department of Pharmaceutics and Social Pharmacy, School of Pharmacy, College of Health Sciences, Addis Ababa University, Addis Ababa, Ethiopia; ${ }^{2}$ Department of Pharmacy, College of Medicine and Health Sciences, Bahir Dar University, Bahir Dar, Ethiopia; ${ }^{3}$ Ethiopian Food and Drug Authority (EFDA), Federal Ministry of Health (FMoH), Addis Ababa, Ethiopia; ${ }^{4}$ Departement of Pharmaceutics and Social Pharmacy, School of Pharmacy, College of Medicine and Health Sciences, Mizan-Tepi University, Mizan-Aman, Ethiopia

\begin{abstract}
A serious viral infectious disease was introduced to the globe by the end of 2019 that was seen primarily from China, but spread worldwide in a few months to be a pandemic. Since then, accurate prevention, early detection, and effective treatment strategies are not yet outlined. There is no approved drug to counter its worldwide transmission. However, integration of nanostructured delivery systems with the current management strategies has promised a pronounced opportunity to tackle the pandemic. This review addressed the various promising nanotechnology-based approaches for the diagnosis, prevention, and treatment of the pandemic. The pharmaceutical, pharmacoeconomic, and regulatory aspects of these systems with currently achieved or predicted beneficial outcomes, challenges, and future perspectives are also highlighted.
\end{abstract}

Keywords: nano-vaccine, nano-theranostics, nanoparticles, nanotechnology, SARS-CoV-2

\section{Introduction}

The end of 2019 came with a serious viral infectious disease which was seen primarily from China, but spread worldwide and was declared as a pandemic in a few months. The outbreak officially became a pandemic in March 2020. ${ }^{1,2}$ The World Health Organization (WHO) termed this novel and vastly spreading disease as "coronavirus disease-2019" (COVID-19), and the viral agent as "severe acute respiratory syndrome - coronavirus-2" (SARS-CoV-2). Since then, it has been a massively challenging global epidemic with combined health-related and economic destitution worldwide. ${ }^{3,4}$ SARS-CoV-2 seriously affects the respiratory system by triggering an acute immunological response which is the main cause of death with a fatality rate per country of $0.05-19.4 \%$. The SARS-CoV-2 results in an increased mucous secretion, which then clogs the alveoli and prevents blood oxygenation. Its endocytosis and replication in the lungs generates an acute immune response and tissue inflammation by triggering the signal cascade through cytokine storms. The virus can also spread to the digestive system and other major organs like the kidney and liver. It has the potential to access every tissue that expresses angiotensinconverting enzyme-2 (ACE2) receptor. ${ }^{5-7}$ Structural analyses of SARS-CoV-2 showed that it has spike (S), envelope (E), membrane (M), and nucleocapsid (N) proteins which are responsible for its cell attachment and entry mechanisms. Management strategies are based on these structural features. More than $80 \%$ of SARS-CoV-2 and host cell membrane interactions occur due to the presence of the
Correspondence: Ashagrachew Tewabe Yayehrad

Department of Pharmaceutics and Socia Pharmacy, School of Pharmacy, College of Health Sciences, Addis Ababa University, PO Box: 9086, Addis Ababa, Ethiopia

$\mathrm{Tel}+251912960525$

Email ashutewabe@gmail.com 
S protein that is a special characteristic of the pathogenic cell for treatment strategies. ${ }^{89}$ Human coronaviruses (HCoVs) are among the top 10 fatal viruses. SARS-CoV, one of the HCoVs, has a mortality rate of up to $10 \%$. Currently, there are approximately 176 million confirmed cases and about 3,811,561 SARS-CoV-2 related deaths worldwide. $^{10}$

\section{Main Symptoms and Related Problems}

Fever (85.6\%), cough (68.7\%), and fatigue (39.4\%) are among the major reported symptoms. Dyspnea, headache, loss of appetite, loss of taste and smell, panting, sore throat, vomiting, diarrhea, rhinorrhea, and abdominal pain are the less common symptoms of the disease. The presence of comorbidities such as hypertension, diabetes, and coronary heart disease may further complicate the problem. ${ }^{11}$ There may be a two-week incubation period with mild to moderate symptoms followed by a high infection rate. Reports showed that there are also asymptomatic transmissions. Currently, the viral outbreak has created a global crisis related to disastrous live losses and financial collapses. ${ }^{1,12}$

\section{Mode of Transmission and Prevention}

The two main ways of COVID-19 transmission are direct air-to-air transmission during sneezing, talking, and coughing; and direct contact with contaminated surface/ object. ${ }^{13,14}$ Personal hygiene, personal protective equipment (PPE), sanitizers, and surface disinfectants such as ethanol $(62-71 \%)$, hydrogen peroxide $(0.5 \%)$, and sodium hypochlorite $(0.1 \%)$ are the main ways of prevention. ${ }^{15-17}$ Moreover, vaccine and drug development is the most eyecatching option to completely fight COVID-19. There is a continuous global effort to explore and decode the exact genome structure, identify the way of infection and transmission, draw effective prevention and immunomodulation approaches, and develop the most effective therapeutics. ${ }^{18}$ However, accurate prevention, early detection, and effective treatment strategies are not yet outlined. There is no approved drug and a free access vaccine to counter its worldwide spread. The various claims on the therapeutic and vaccine development, under various clinical trial phases, did not reach the market yet. ${ }^{19}$ At present, the health care and clinical research approaches are being negatively impacted by the pandemic through restrictions in funding and mobility which necessitate innovative lifesaving ideas and alternative funding sources. ${ }^{20}$

\section{Diagnostic and Management Approaches}

The laboratory diagnosis of this viral infection is based on the techniques like polymerase chain reaction (PCR) and sequencing (smears taken from the oral cavity and throat); computer tomography, which reveals ground-glass opacity in the lungs, indicating viral pneumonia; plain chest radiography which investigates inflammatory foci caused by the virus, fibrosis, and connective tissue occlusions in the lungs that may develop after the disease; ultrasound investigation of the lungs for the visualization of pulmonary and pleural conditions in patients with suspected COVID-19; immunoassays which reveal the substances of protein nature including viruses, and general and biochemical blood test detecting changes in blood parameters related to the infection. ${ }^{9}$ Three main steps for an effective management approach considering the interaction of the virus when invading the host cells: cell attachment and entry, replication and protein expression, then finally, assembly, maturation, and exocytosis. ${ }^{21}$ Based on this concept, there are four medical approaches: vaccination, cell entry (cell cycle) inhibition, immune response modulation, and prophylactic treatment. ${ }^{22}$

There are two major drug therapy strategies against the virus: drug repurposing and novel drug discovery. Drug repurposing is trying to combat the pandemic with primarily discovered drugs for other known therapeutic purposes. This is a feasible strategy since it shortens the drug discovery time. In this regard, lividomycin, quisinostat, spirofylline, burixafor, pemetrexed, edotecarin, diniprofylline, fluprofylline, chloroquine (CQ), hydroxychloroquine (HCQ), remdesivir, tocilizumab, lopinavir/ritonavir, ivermectin, and azithromicin demonstrated potential antiCOVID effects. In addition, combined zinc supplements with CQ, drugs like silibinin and doxepin, and some glucocorticoids (betamethasone, dexamethasone, hydrocortisone, fludrocortisone, ciclesonide, and triamcinolone) showed promising effects. ${ }^{23-25}$ Figure 1 demonstrates their mechanism of action and interaction at different stages of the viral cell cycle. ${ }^{26}$ Repurposed drugs have previously established safety profiles which facilitate their clinical transition, and result in less risky and more rapid applications. Different insilico tools can be combined with large drug databases for selecting "possible candidates" from the available pharmaceutical and pharmacological substances. ${ }^{27,28}$ Molecular dynamics simulations of HCQ and azithromycin dual therapy demonstrated a promising effectiveness with different potential mechanisms of action against the open and closed viral protein 


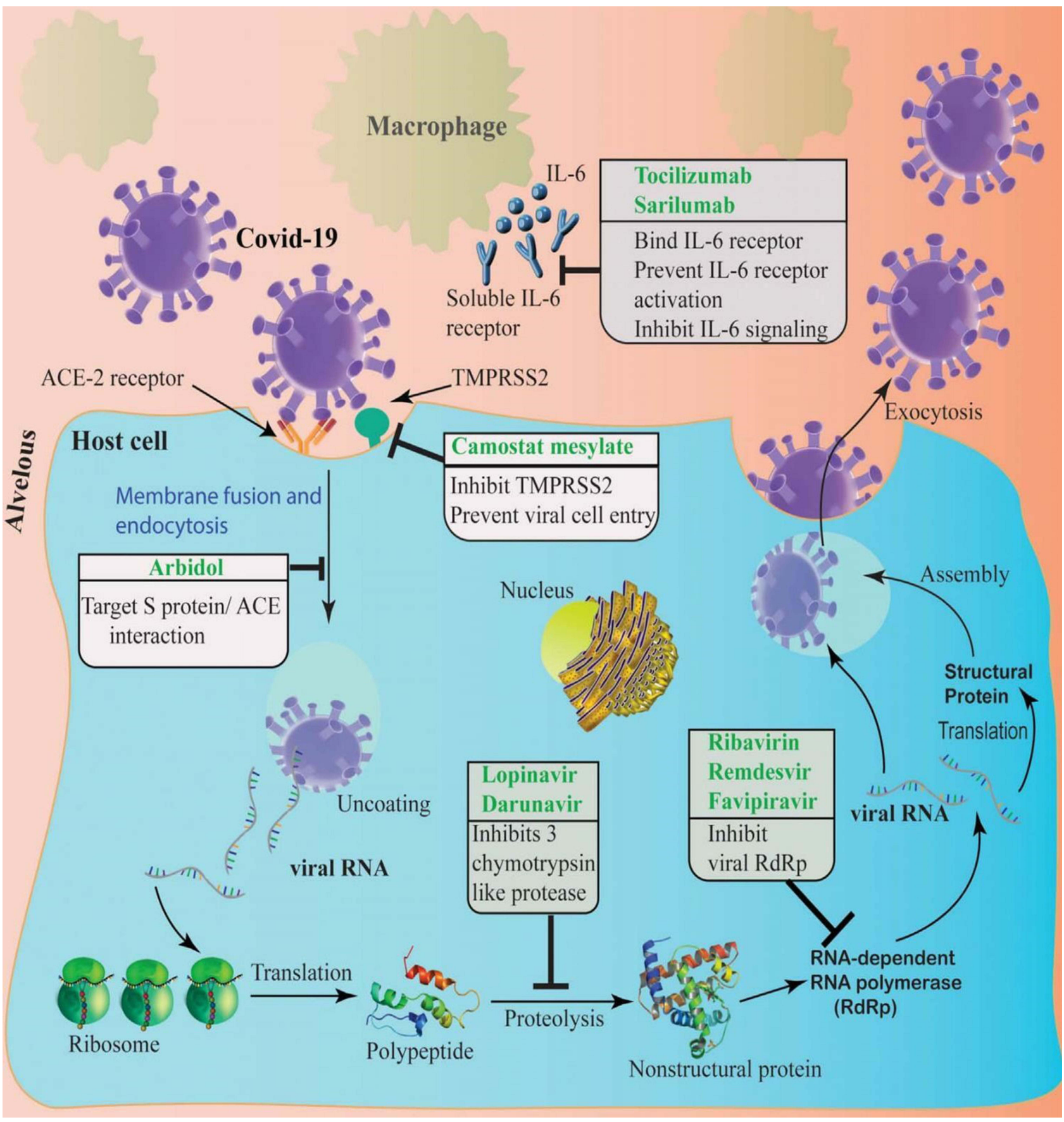

Figure I COVID-19 entry point and possible target point of repurposed drug. Copied from Ahmad MZ, Ahmad J, Aslam M, Khan MA, Alasmary MY, Abdel-WAHAB BA. Repurpuse drugs against COVID-19: nanomedicine aas an approach for finding new hope in old medicines. Nano Express. 2021;2:022007. doi:10.1088/2632-959X/abffed. ${ }^{26}$

forms. $^{29-31}$ HCQ-azithromycin combination approach showed a better clinical outcome in terms of mortality rates among elderly patients, intensive care unit transfers, length of hospital stay, and duration of viral shedding. ${ }^{30} \mathrm{~A}$ systematic review, meta-analysis, and trial sequential analysis of ivermectin indicated that, using ivermectin for the prevention and treatment of COVID-19 is an equitable, acceptable, and feasible approach. The study strongly suggested that thehealth professional should consider its use both in therapeutic and prophylaxis approaches. ${ }^{32}$ Remdesivir, lopinavir/ritonavir, lopinavir/ritonavir with interferon beta-1 and CQ or HCQ are being assessed in clinical trials. However, these are associated with statistically insignificant clinical outcomes, complicated mortality/morbidity data reports, and unconfirmed clinical effects which prohibited the trustful use of those drugs. ${ }^{33,34}$ In 
contrast, the new drug discovery approach is more complicated and time-consuming. However, it has the highest potential to find new pharmaceuticals which have unique advantageous properties for unique viral pandemic events. $^{25}$

Biomaterials can endorse the fight against COVID-19 by enhancing immunomodulation and anti-inflammatory effects. Monoclonal antibodies can cross-react with SARS-CoV-2, block the viral attachment by disrupting the receptor-binding interface, and inactivate the virus by binding to $\mathrm{S}$ proteins. ${ }^{35,36}$ Tocilizumab (monoclonal antibody against interleukin (IL)-6), sarilumab (IL-6 receptor antagonist), HCQ, and CQ (blockers of pro-inflammatory cytokines) can be used as immunomodulators to counteract the systemic hyperinflammation. ${ }^{37-39}$ Biologicals are the foremost approaches in COVID-19 management. Convalescent plasma therapy (CPT) can neutralize SARS-CoV-2 in newly infected patients. ${ }^{40}$ Different inactivated and recombinant vaccines are now being developed from viral DNA fragments and they are being evaluated in different phases of many clinical trials. ${ }^{41}$

Scientists are still searching for the most appropriate, efficient, and effective diagnostic, therapeutic, and preventive strategies, including the use of new nano-based technologies. Nanotechnology-based research and development now appears to be essential to end the pandemic effectively and shortly. ${ }^{34}$ Nano-based detection with nanowire biosensor chips, graphene derivatives, and other types of nanostructures have been developed. ${ }^{9}$ Nano-based systems are effective for inhibiting pathogens and minimizing drug resistance profiles. ${ }^{42}$ Carbon nanotubes that demonstrated a noble nanocarrier property and enhanced drug release towards target cells in cancer therapy can be potential therapeutic alternatives against SARS-COV$2 .^{43,44}$ Currently, many pharmaceutical research and manufacturing companies are turning to the use of nanotechnology for vaccine and drug development. Nanoparticles (NPs) are being increasingly investigated and used as new anti-SARS-CoV agents, vaccine carriers or adjuvants, and nanoscale biorecognition elements with a promising indication of nanomedicine as a potentially suitable option to end the fight against this pandemic. ${ }^{34,45}$

\section{Nanostructure-based COVID-I 9 Management}

Nanostructured material is a type of material with at least one nanometric dimension (usually less than $100 \mathrm{~nm}$ ). They can be organic, inorganic, biomaterial-based, and carbon-based $^{46}$ as shown in Figure 2. Their physicochemical properties such as, chemical reactivity, size-dependent transport, biocompatibility, and reduced toxicity attracted scientists in many fields. Medicine is one such fields with rising attention in applying nanotechnology. ${ }^{42}$ Nanostructure-based delivery systems demonstrated improved specificity and bioavailability over the traditional system. Much of the added value is related to NP

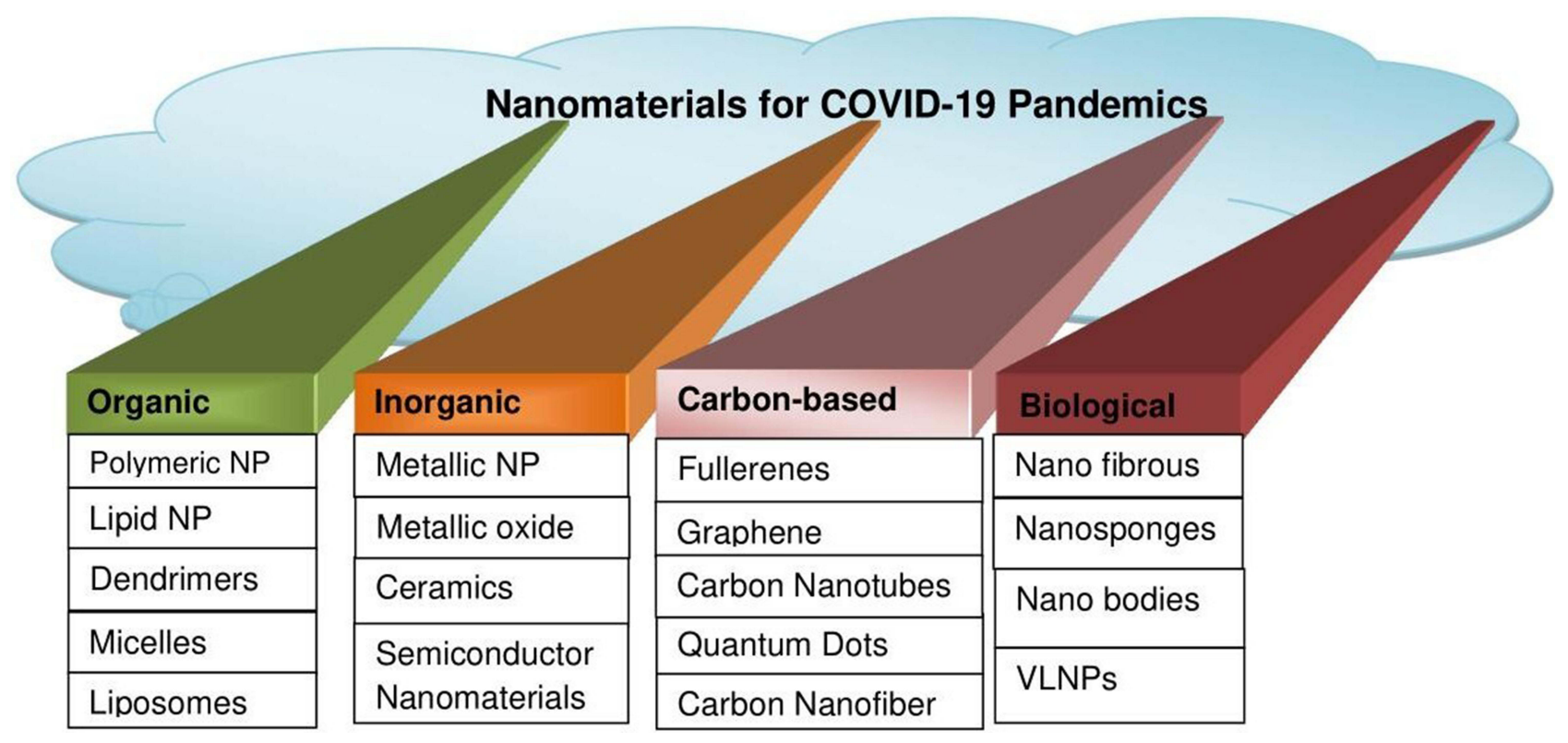

Figure 2 Different nanomaterials used against COVID-19. 
physicochemical properties which include controllable size, great surface area to mass ratio, and easily functionalizable structure. They can stabilize the drug in the systemic circulation for targeted, controlled, and sustained delivery, which, as a result, can increase the therapeutic advantage. ${ }^{47}$ Multiple targeting, in vivo imaging, and combined drug delivery are also their potential advantages. ${ }^{48}$ All these principles can be applied to fighting the COVID19 pandemic.

\section{Why Nanostructure-based COVID-19 Management?}

As the pandemic continues to cause an enormous global crisis, there is still an unmet need to discern a favorable, safe, and typically effective approach for diagnosis, treatment, vaccination, and prevention to prohibit superspreading of the virus and a mortality crisis. ${ }^{49}$ Diverse nanotechnological strategies have shown a promising capacity to address many of those unmet needs in the fight against the pandemic as stated in the next sections.

\section{Challenges in Biosafety}

COVID-19 exposed the world for too many discrepancies including an absence of effective vaccines and therapeutics, lack of rapid or real-time detection methods, shortage of protective equipment, and limitation in accessibility of support for infected patients. These biosafety problems arise mainly from limited research and considerations in materials science. A variety of nanostructured materials, such as polymers, inorganic-organic frameworks, biomaterials, graphene derivatives, and carbon nanotubes are radically transforming the way of countering biosafety challenges. ${ }^{50}$

\section{Detection Time, Accuracy and Sensitivity}

Time-consuming detection processes like quantitative realtime PCR can be eradicated by applying NP-mediated sensing alternatives which can provide a rapid diagnosis. ${ }^{51}$ Limitations in antibody tests like technical production and identification problems, lack of suitability, and false positive or negative findings are reported from the conventional tests. Early stage detection, no or minimized contamination, and protected risk of error are also questions to be answered with more appropriate advances of testing. ${ }^{52}$

\section{The Gap Between Diagnostics and Therapy}

Recently, the application of NPs has emerged as groundbreaking in the medical field that allows accurate diagnosis and specific treatment of a disease at once (theranostic approach). Nanotheranostics involve virus detection and simultaneous neutralization by using nanodrugs that target diagnostics and therapy. ${ }^{53}$ This approach helps to fill the existing gap between diagnostics and therapy. It has been widely demonstrated in cancer chemotherapeutic investigations and there have been substantial struggles to extend this advantage to other areas of medicine including infectious diseases. $^{54}$

\section{Unsupported Benefits of Repurposed Drugs}

Even though drug repurposing is a time-saving approach, the benefits of the repurposed drugs could not be fully supported with clinical outcomes and respective authorities. Unsatisfactory results from CQ and CQ, hepatotoxicity of remdesivir, unestablished harm or benefits of ACEIs, challenging safety/efficacy issues from the nonspecific mechanism of CPT, and safety concerns on corticosteroid use were reported. Application of nanostructures to the repurposed drugs can help develop efficient therapeutic strategies with minimal safety/efficacy concerns. ${ }^{52}$

\section{Targeting and Controlling Release}

SARS-CoV-2 mainly affects the respiratory tract, especially the lungs, with expanded effects on other organs such as the gut, kidney, and vasculatures. ${ }^{55}$ Therefore, the lungs are the most important organ for COVID-19 drug delivery. Targeting such sites and controlling drug release at target organs with conventional approaches is very difficult. Advances in inhalable NPs overwhelm such disadvantages, such as side effects from high serum drug concentrations and target inaccessibility. Nanotechnology-based intranasal drug delivery systems can overcome various limitations of mucosal administration. ${ }^{34}$ More accurate and controlled crossing of the blood-brain barrier (BBB) can be achieved with nanobiomaterials that can improve cell retention, survival, differentiation, and integration inside the CNS. ${ }^{56}$ Nanodelivery through the nasal cavity is not only simple and inexpensive, but also noninvasive and rapidly absorptive. ${ }^{57}$ In addition, biocompatible nanomaterials such as boron nitride oxide nanosheets can improve the adsorption of drugs towards different parts of the viral protein; help the drug diffuse rapidly to the viral protein, and improve drug-virus interaction. ${ }^{31}$

\section{Vaccine Effectiveness, Stability and Release}

Conventional vaccines have limited efficacy against novel pathogens due to their low blood stability as well as short and insufficient immune response that drives the need for 
higher doses. ${ }^{58}$ In addition, they are associated with short half-life, poor immunogenicity, non-targeting, slow absorption, and high storage and delivery requirements. Nanobiomaterials can be used as adjuvants for vaccines with special characteristics of reduced systemic toxicity and better targeting. ${ }^{59}$ There are also associated challenging issues, such as high pathogenic variety, high viral mutation rate, and complex host-related failures, resulting in an inappropriate immune response. ${ }^{52}$ Nanovaccinology comes with an effective alternative that results in strong immunostimulatory effects, manageable size and surface properties, controllable drug release, and strong stimulation of humoral and cellular responses. ${ }^{60}$

\section{Surface Disinfection Efficacy and Duration}

Disinfecting all surfaces and objects all the time is practically impossible, and one cannot be sure that the surface/object will not be contaminated again. Surface coating with nanomaterials that can inactivate the viral cell can be an advantageous advance for designing contamination-free equipment. Self-disinfecting surfaces can be prepared using nanomaterials with intrinsic antipathogenic effects. ${ }^{9,61}$ Surfaces with inherent virucidity, antimicrobial releasing self-sanitizing surfaces, and surface topologies with viral self-deactivation are some among the novel surface nanodisinfecting applications. $^{62}$

\section{Protective Efficiency, Safety and Duration}

As PPE plays the greatest role in combating the pandemic, it is equally essential to critically consider their sufficient supply, storage, waste management, and appropriate use. ${ }^{63}$ Actually, the current trend of applying the PPE could not eliminate the viral transmission as expected which necessitates a modification for their production and use. ${ }^{64}$ Environmental safety and waste management related to PPE is another complicated issue during the pandemic season as it becomes burdensome, resulting in a health compromising situation including carcinogenic health impacts. Therefore, it is recommended to use available alternative technologies for the production of biomedical equipment and treatment of COVID-19-related waste. ${ }^{65,66}$ Moreover, disposable PPE becomes one of the major factors in environmental pollution and source of biohazards creating critical environmental issues globally. If this remains unsolved, it may be a long-term threat to human and aquatic organisms. ${ }^{67-69}$ This can be potential longterm physical, physiological, and pathophysiological effects. $^{70}$ Nanostructures can improve PPE efficacy and safety by providing reusable, self-cleaning, high efficiency, and effective products with antimicrobial and antiviral properties. Intrinsic antiviral NPs, nanofibers and NPcoatings that can provide super-hydrophobicity, waterrepelling, synergistic, and self-cleaning effects are some of the applicable nanostructures. ${ }^{71,72}$ Nanotechnology can generally convey advanced therapeutic, diagnostic, and prevention options than conventional as summarized in Table 1.

\section{Nanostructure-based Approaches in COVID-19 Management}

Nanotechnology has huge potential for fighting the COVID-19 pandemic, since it enables targeted drug or vaccine delivery to physiologically inaccessible targets; increases drug loading and transport, and provides intrinsic/synergistic virucidal activity. ${ }^{73,74}$ It can also possess simple, fast, and cost-effective alternative disinfection methods; provide targeted pulmonary drug delivery, and offer ways for designing better immunomodulating materials. It can generally contribute to antimicrobial, antiinflammatory, diagnostic, theranostic, therapeutic, biosensing, preventive/protective equipments, immunomodulation, and vaccination approaches against the pandemic. ${ }^{61,75}$ The different application of nanotechnology during the fight against the COVID-19 pandemic is summarized in Figure $3 .^{76}$ NPs possess a comparable size and structure with the virus as they both act at the same nanoscale, that makes their use paramount and suitable for the development of vaccine and immune engineering. This also allows the NPs to bind, encapsulate and passivate the virus, permitting easily detection, treatment, and prevention. ${ }^{77,78}$ Generally, nanomaterials can induce an external stimulus that is responsible for killing the virus or directly interact with the virus with their surface properties to act as antiviral agents. ${ }^{25}$ Nanodiagnostics, surveillance and monitoring, nanotherapeutics, and nanovaccination can provide the next generation of fighting approaches against the outbreak. ${ }^{53,79}$

\section{Nanodiagnostic Applications}

Nanotechnology, in SARS-CoV-2 detection, can be applied in the form of nucleic acid testing (amplification of nucleic acid with NPs under isothermal conditions); point-of-care testing (POCT) (diagnose infected individuals, without the need of sending patient samples to laboratories via simple color changes after applying nanostructures); electrochemical sensors (high sensitivity and 
Table I Comparison Between the Conventional and Nanobased COVID-19 Management Approaches

\begin{tabular}{|c|c|c|}
\hline & Conventional Approach & Nanotechnology-based Approach \\
\hline Diagnosis & $\begin{array}{l}\text { - Lengthy time of detection } \\
\text { - Limitations in antibody tests like technical produc- } \\
\text { tion and identification problems } \\
\text { - Lack of suitability } \\
\text { - False positive or negative findings }\end{array}$ & $\begin{array}{l}\text { - Early stage detection } \\
\text { - No or minimized contamination } \\
\text { - Protected error risk } \\
\text { - Sensitivity } \\
\text { - Possibility of miniaturization with metallic NPs } \\
\text { - NPs conjugated with corona virus specific antibodies }\end{array}$ \\
\hline Treatment & $\begin{array}{l}\text { - Absence of effective therapeutics } \\
\text { - Low surface area to mass ratio } \\
\text { - Chemical reactivity/instability } \\
\text { - Side effects from high serum and non target } \\
\text { - Inaccentrations } \\
\text { - Inility of the target by the drug }\end{array}$ & $\begin{array}{l}\text { - Stabilized in the systemic circulation } \\
\text { - Targeted, controlled and sustained delivery } \\
\text { - Controllable size and size-dependent transport, } \\
\text { biocompatibility } \\
\text { - Reduced toxicity } \\
\text { - Theranostic approach } \\
\text { - Noninvasive administration like inhalations }\end{array}$ \\
\hline Vaccines & $\begin{array}{l}\text { - Low blood stability, slow absorption and short half- } \\
\text { life } \\
\text { - Insufficient immune response } \\
\text { - Higher doses - risk for side effects } \\
\text { - Poor immunogenicity, non targeting, slow } \\
\text { absorption } \\
\text { - High storage and delivery requirements }\end{array}$ & $\begin{array}{l}\text { - Multiple targeting } \\
\text { - Strong immuno stimulatory effects } \\
\text { - Manageable size and surface properties } \\
\text { - Reduced adverse effects } \\
\text { - Controllable drug release } \\
\text { - Strong stimulation of humoral and cellular responses }\end{array}$ \\
\hline $\begin{array}{l}\text { Personal protective } \\
\text { Equipment (PPE) }\end{array}$ & $\begin{array}{l}\text { - Shortage of supplies } \\
\text { - Low filtration efficiency } \\
\text { - Single-use (use-and-throw) - economic, eco-safety } \\
\text { and waste management problems } \\
\text { - Breathing pressure and heat dissipation } \\
\text { - Ineffective disinfection and sanitizing }\end{array}$ & $\begin{array}{l}\text { - Reusable and improved bio-safety } \\
\text { - Self-cleaning, high efficiency and effective disinfectants with } \\
\text { antimicrobial and antiviral properties } \\
\text { - Designing contamination-free equipment } \\
\text { - Adding inherent virucidity to surfaces } \\
\text { - Antimicrobial releasing self-sanitizing and surface topolo- } \\
\text { gies with viral self-deactivation }\end{array}$ \\
\hline
\end{tabular}

possibility of miniaturization with metallic NPs); chiral biosensors (NPs conjugated with coronavirus specific antibodies), etc. ${ }^{80,81}$

\section{Point-of-care Diagnostics (POCD)}

Since the infection is easily transmissible from human to human, the diagnostics should better be at POC without the need for experienced labor, complex time-taking procedures, and sophisticated laboratories. ${ }^{82}$ POCD provides a diagnostic outcome with improved laboratory quality in real-time, within minutes and not hours. Nanotechnology can further advance the POCD approach by adding nanoensor technology, microfluidic channel devices, bio-analytical platforms, assay formats, lab-on-a-chip technologies, and complementary advances. ${ }^{83}$ NPs can assist the immunochromatographic test (ICT), also known as lateral flow immunoassays (LFIA), for detecting the antigens or antibodies rapidly with a POC. The advantages of this system includes; detection of both symptomatic and asymptomatic patients, not requiring trained staff, triage of patients avoiding further spreading, diagnosis when laboratory facilities are unavailable, easy of use, small sample amount, and timely detection in less than 20 min. $^{84,85}$

\section{Rapid Diagnostic Kits}

The principle of rapid diagnostic kits works by direct isolation of RNA from a patient sample. Metallic and magnetic NPs, such as gold and iron oxide NPs, have been widely investigated so far and demonstrated improved testing accuracy, specificity, time, and reliability. ${ }^{86,87}$ Gold NPs coupled to complementary DNA sequences demonstrated a color change from red to blue indicating the formation of a tertiary complex with the viral antigen after the immobilization and agglomeration of the NPs. ${ }^{88}$ Metal oxide NPs in complement with a silicon-on-insulator nanowire sensor showed a rapid and 


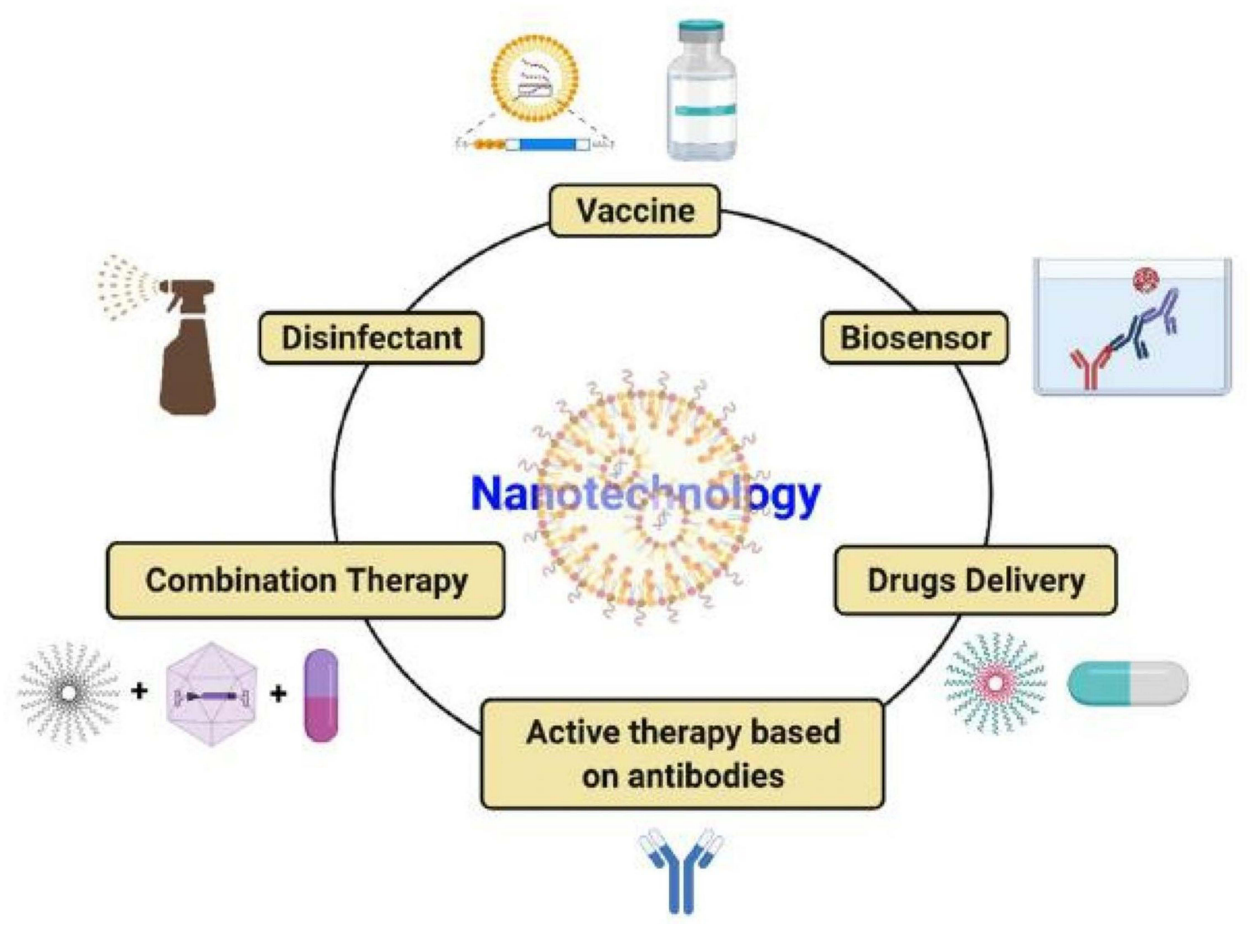

Figure 3 Potential nanotechnology applications for combating SARS-COV-2. Copied from Rai M, Bonde S, Yadav A, et al. Nanotechnology as a shield against COVID-I9: Current advancement and limitations. Viruses. 2021;13:1224. doi: 10.3390/v1307/224. ${ }^{76}$

very sensitive SARS-CoV-2 antibody detection in 5-15 min. Magnetic NPs (MNPs), especially iron oxide NPs, can easily separate the viral RNA from sample solution with their high magnetic efficiency to prepare analyte preconcentration, signal amplification, and biosensing. ${ }^{8,89}$ Silica-coated super-paramagnetic NPs improved the selectivity of the detection during PCR-based assays by forming magnetic-conjugated DNA complexes, which then can be magnetically separated and amplified through PCR. ${ }^{90}$ Field-effect transistors based on graphene demonstrated the most rapid SARS-CoV-2 detection in less than a minute. ${ }^{91,92}$ The precision of PCR can also be enhanced by using graphene NPs. ${ }^{93}$

\section{Nanostructured Biosensors}

NP-based biosensors can minimize the conventional timeconsuming steps, like in the case of quantitative real-time PCR, and provide pronounced advances in rapid diagnosis. ${ }^{51}$ The SARS-CoV-2 biosensor using thiol-modified antisense oligonucleotide-capped glyconanoparticles can diagnose positive COVID-19 cases visible with the naked eye through color change within 10 min. $^{84}$ The glyconanoparticle platform with a lateral flow diagnostic device demonstrated a low-cost and rapid detection in less than $30 \mathrm{~min}^{94}$ Nanobiosensors integrated with bio-informatics can provide individualized approaches by correlating infection progression with sociodemographic parameters like race, gender, age, and region that can further optimize targeted testing, tracing of asymptomatic patients (carries), and detection of discharged patients for re-infection. ${ }^{95}$ Different nanostructured biosensor applications are presented in Figure 4. ${ }^{96}$

\section{Nanomaterial-based Detection Using Smartphone}

Nanopapers and nanochannels are nanomaterial-based sensors that advance the lateral-flow devices to detect at observation level with smartphones or the naked eye. They offer cost-efficient options for viral detection. Battery-operated and smartphone camera-based amplifications with inorganic quantum dots are coming to be the next generations for SARS-CoV-2 detection. ${ }^{97}$ Smartphone-based sensing systems are semi-automated, personally accessible, userfriendly, and applicable with less training. The sensing system is connected to the smartphones; NPs are employed peripherally; analysis is conducted by the sensing system, and finally, the smartphone itself will interpret the results. It is individualized and takes less time than PCR. ${ }^{98}$ Some examples of nanomaterials investigated for diagnosis of COVID-19 are listed in Table 2. 


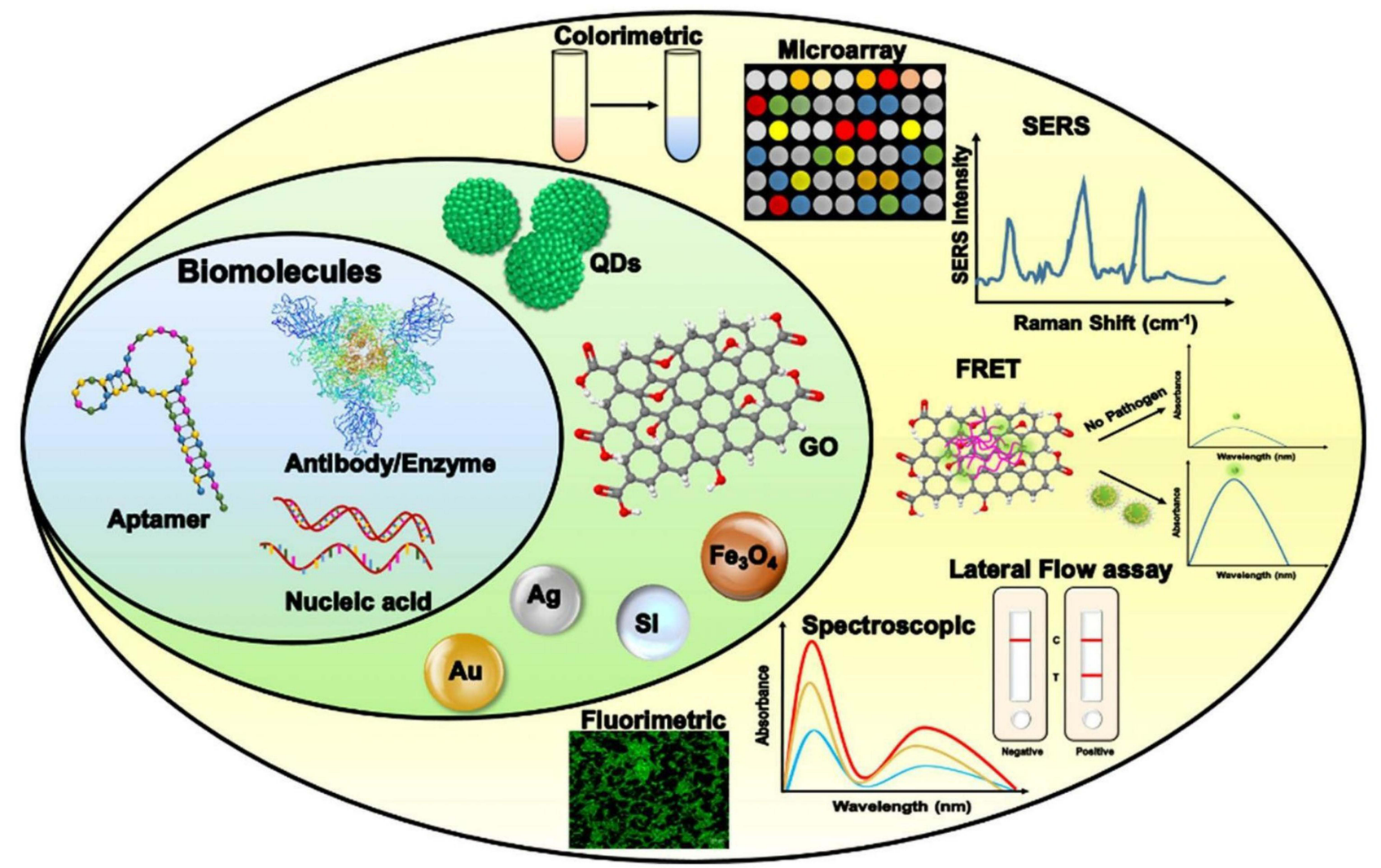

Figure 4 Application of biorecognition elements of a biosensor to develop a sensing platform against SARS-CoV-2. Copied from Gupta R, Sagar P, Priyadarshi N, et al. Nanotechnlogy-based approaches for the detection of SARS-CoV-2. Front. Nanotechnol. 2020;2:589832. doi: 10.3389/fnano.2020.589832. ${ }^{96}$

Abbreviations: FRET, Förster resonance energy transfer; GO, graphene oxide; SERS, surface-enhanced Raman spectroscopy; QD, quantum dot.

\section{Nanotheranostic Applications}

In recent times, nanostructured systems have brought a groundbreaking advance in medicine, in which accurate detection and specific therapeutics of disease conditions can be conducted at once (theranostic approach). Theranostics can provide detection and neutralize the viruses using NP-based approaches which will possess a great prospective in controlling the COVID-19 pandemic as NPs can amplify the detection, inhibit viral replication, and disrupt all possible virus-host interactions. Thus, nanotheranostics can fill the existing gap between diagnostics and therapy. ${ }^{53,54}$ Nanotheranostics is a new field in medicine that combines NP-based targeted therapy based on diagnostic tools to efficiently and selectively deliver drugs, vaccines, and biologicals to the target sites of infection. It has the ability to monitor infectious sides, deliver treatments, and assess therapeutic responses with noninvasive imaging approaches. ${ }^{105,106}$

Several approaches are being investigated for smart nanotheranostic application by combining bioactive targeting and nanodiagnostics to deliver therapeutics with concomitant real-time response monitoring; minimized probability of over- or under-dosing, and noninvasive imaging techniques. Nuclear imaging with radiolabeled nanomaterials, inorganic NPs, organic NPs like polymers, carbon-based nanomaterials, and vesicular nanostructures like nanosomes, are some of the multifunctional nanotheranostics. ${ }^{107}$ The application of quantum dots in fluorescence imaging technology enables in vivo visualization of individual cellular behaviors, and simultaneous treatment according to the observed behavior at the same time. ${ }^{108}$ Nanorobots can outline a roadmap for nanotheranostics against a variety of diseases including the recent pandemic. Artificial intelligence can help this advance with multivariate data analysis regarding the disease pathophysiology and design of its more efficient therapeutics. Patient-specific models and nucleic acid-based nanorobots with more advanced nanoplatforms and multivalent nanostructures are being considered as promising theranostics against the pandemic. ${ }^{50}$

\section{Nanotherapeutic Applications}

Therapeutic nanostructures can block viral entry, inhibit its replication, deliver drugs as nanocarriers into the target organ, 
Table 2 Some Nanobased Novel Diagnostic Tools for COVID-19 Detection

\begin{tabular}{|c|c|c|c|c|}
\hline $\begin{array}{l}\text { S } \\
\text { No. }\end{array}$ & Nano-Formulation & Features of the Nanoformulation & Reported Benefits of Nanoforms & Reference \\
\hline I. & $\begin{array}{l}\text { Dual-functional plasmonic } \\
\text { photothermal biosensor }\end{array}$ & $\begin{array}{l}\text { The two-dimensional gold nanoislands (AuNIs) } \\
\text { functionalized with complementary DNA receptors }\end{array}$ & $\begin{array}{l}\text { - Sensitive detection of the selected } \\
\text { sequences } \\
\text { - Precise detection of the specific tar- } \\
\text { get in a multi-gene mixture }\end{array}$ & 88 \\
\hline 2. & $\begin{array}{l}\text { Graphene-based field- } \\
\text { effect transistor } \\
\text { biosensing devices }\end{array}$ & $\begin{array}{l}\text { Graphene NP-based sensors coated with specific } \\
\text { antibodies against SARS-CoV- } 2 \mathrm{~S} \text { protein }\end{array}$ & $\begin{array}{l}\text { - Specific targeting of } \mathrm{S} \text { protein } \\
\text { - Low concentration detection } \\
\text { - Highly sensitive, rapid and on-site } \\
\text { detection }\end{array}$ & 92 \\
\hline 3. & $\begin{array}{l}\text { COVID-19 rapid test } \\
\text { cassette (SureScreen } \\
\text { Diagnostics Ltd) }\end{array}$ & $\begin{array}{l}\text { Au NPs embedded in the nitrocellulose test strip } \\
\text { integrated with lateral flow devices }\end{array}$ & $\begin{array}{l}\text { - High sensitivity and reliability of visual } \\
\text { detection } \\
\text { - Used in point-of-care (on-site) } \\
\text { detection } \\
\text { - Significant time and cost saving } \\
\text { - Detection even in mild or asympto- } \\
\text { matic cases } \\
\text { - Easy to use and read }\end{array}$ & 99 \\
\hline 4. & $\begin{array}{l}\text { Smart Detect SARS-CoV- } \\
2 \text { rRT-PCR kit }\end{array}$ & $\begin{array}{l}\text { Nanobiomaterial of oligonucleotide primers and } \\
\text { probes labeled with fluorescent reporter dyes and } \\
\text { quenchers }\end{array}$ & $\begin{array}{l}\text { - Single-well detection of } 3 \text { different } \\
\text { targets } \\
\text { - Endogeneous control informs effec- } \\
\text { tiveness of procedures/overall speci- } \\
\text { men quality }\end{array}$ & 100 \\
\hline 5. & $\begin{array}{l}\text { Chiral zirconium } \\
\text { Quantum dots }\end{array}$ & $\begin{array}{l}\text { Nanocrystals for optical detection synthesized using } \\
\text { L(b)-ascorbic acid }\end{array}$ & $\begin{array}{l}\text { - Greater sensitivity than conventional } \\
\text { ELISA methods }\end{array}$ & 101 \\
\hline 6. & $\begin{array}{l}\text { CRISPR-based DETECTR } \\
\text { lateral flow assay }\end{array}$ & $\begin{array}{l}\text { Using synthetic, in vitro transcribed SARS-CoV-2 } \\
\text { RNA gene targets in nuclease-free water }\end{array}$ & $\begin{array}{l}\text { - Rapid ( } 30 \mathrm{~min}) \text {, low-cost, and } \\
\text { accurate } \\
\text { - } 90 \% \text { sensitive and 100\% specific for } \\
\text { detection } \\
\text { - No cross-reactivity for related coro- } \\
\text { navirus strains }\end{array}$ & 102 \\
\hline 7. & $\begin{array}{l}\text { Lanthanide-doped NP- } \\
\text { based lateral flow } \\
\text { immunoassay }\end{array}$ & $\begin{array}{l}\text { Self-assembled lanthanide-doped polysterene NPs } \\
\text { dispensed by recombinant nucleocapsid } \\
\text { phosphoprotein }\end{array}$ & $\begin{array}{l}\text { - Rapid and sensitive lateral flow } \\
\text { immunoassay } \\
\text { - Useful for progression monitoring } \\
\text { and evaluating } \\
\text { - patients' response to treatment }\end{array}$ & 103 \\
\hline 8. & $\begin{array}{l}\text { Magnetic NPs for RNA } \\
\text { extraction and isolation }\end{array}$ & $\begin{array}{l}\text { Synthesis of polymer coated amino-magnetic NPs } \\
\text { (Poly-NH2-MNP) }\end{array}$ & $\begin{array}{l}\text { - Rapid detection } \\
\text { - Allows processing of } \sim 10,000 \text { tests } \\
\text { per day } \\
\text { - Guaranteeing to reach a wide range } \\
\text { of population }\end{array}$ & 104 \\
\hline
\end{tabular}

Abbreviations: ELISA, enzyme-linked immunosorbent assay; MNP, magnetic nanoparticle; NP, nanoparticle; rRT-PCR, real-time reverse transcription polymerase chain reaction.

and assist vaccine formulation and delivery as summarized in Figure 5. In general, they target the SARS-CoV-2 entry and life-cycle with a special emphasis on the $\mathrm{S}$ protein as it is the most important factor for viral entry and host cell interactions. ${ }^{45,80}$ Nanomodification of repurposed drugs like dexamethasone and CQ demonstrated promising anti-edema, antifibrotic, and anti-inflammatory mechanism predicting NPuptake in cells. ${ }^{109,110}$ Nanostructure-based drug delivery can 


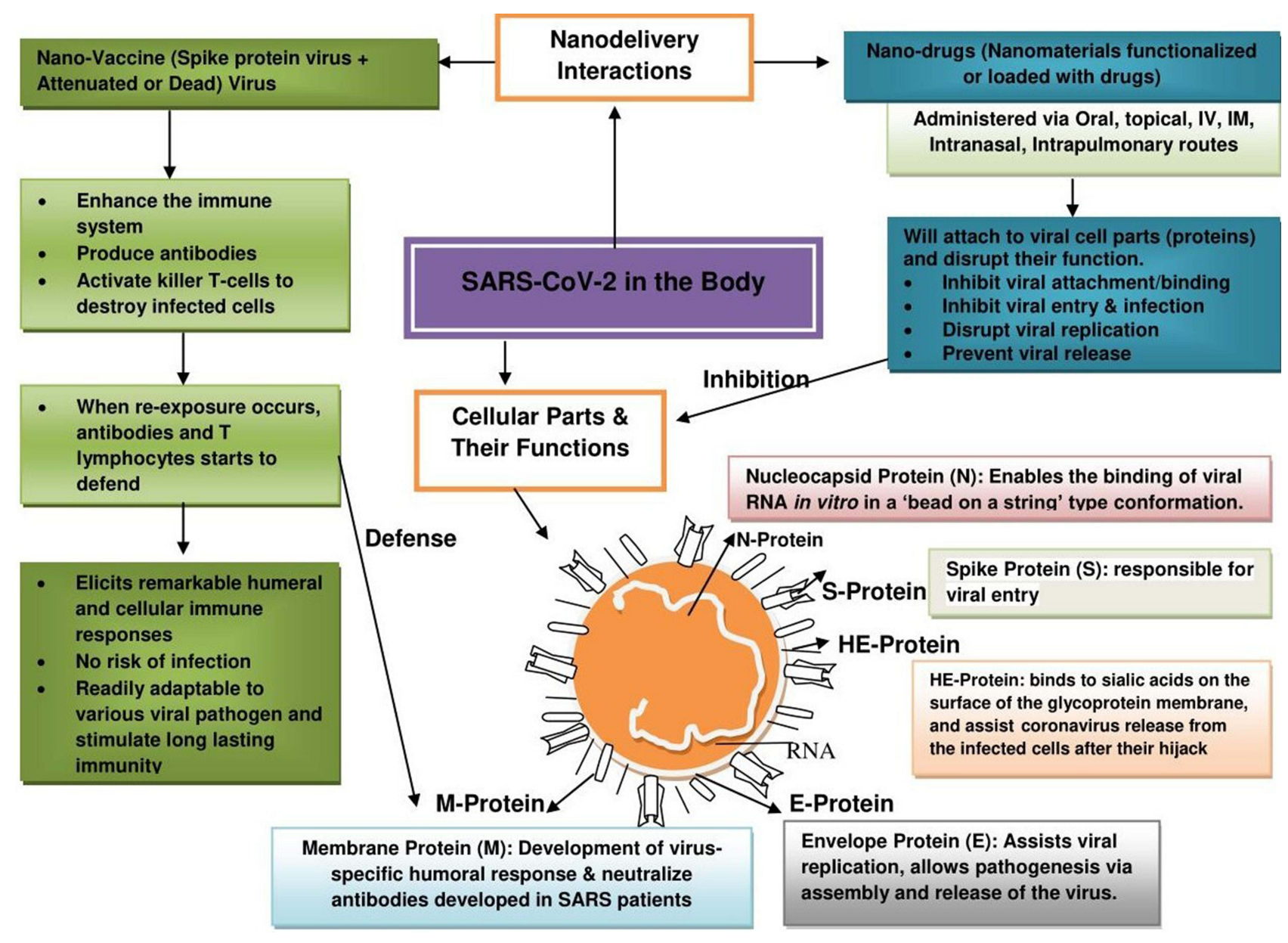

Figure 5 Summary of cellular parts of SARS-CoV-2, their functions and interactions with nanodelivery management mechanisms.

be either passive (drugs loaded and transported with nanocarriers) or active self-delivery (drug molecules themselves are nanosized). ${ }^{111}$ Since SARS-CoV-2 initiates its infection on the nasal cavity, nasal cavity-based nanodelivery is very important and promising for targeted COVID-19 management with simple, inexpensive, noninvasive, and rapidly absorbable approach. ${ }^{57}$ These systems are believed to improve therapeutic efficacy without compromising safety. Several nanodeliveries with enhanced antiviral activities against SARS-CoV-2 have been investigated, reported, and it is claimed that they can synergize the global fight against the pandemic. ${ }^{112}$ Some examples from these investigations are described in Table 3.

\section{Organic and Inorganic Nanoparticles}

Organic NPs such as liposomes, dendrimers, micelles, and polymers can have nanovirucidal effects and inactivate viral cells including SARS-CoV-2. They can be formed in combination with each other or with inorganic NPs to form hybrid nanosystems based on specific use at the targeted site. ${ }^{74}$
Inhalable organic and inorganic NPs (Figure 6) ${ }^{121}$ can be used for targeting the lung to overcome side effects from high serum concentrations of conventional administrations. ${ }^{122}$ Nano-drug co-deliveries can reduce particle size-dependent safety issues in lung and respiratory systems. ${ }^{123}$ Corticosteroid-loaded PLGA NPs, solid lipid NPs, N,Ndimethylaminoethyl methacrylate, and butyl methacrylate monomers can be used for effective and safe pulmonary delivery to prevent systemic immunosuppression effects of the drugs. ${ }^{124}$ Inorganic NPs like transition metal NPs (Ag, $\mathrm{Cu}, \mathrm{Zn})$, metal oxides $\left(\mathrm{Fe}_{2} \mathrm{O}_{3}, \mathrm{TiO}_{2}, \mathrm{ZnO}_{2}\right.$ ), and carbonbased NPs have intrinsic antipathogenic effects by interfering one or more viral life-cycle stages. ${ }^{125}$ Mesoporous silica NPs provide drug co-delivery which can further be functionalized with ligands for active targeting of the viral cell. ${ }^{8}$ AgNPs are better drug carriers for nucleic acid-based delivery with increased stability, protection from degradation, and controlled intracellular delivery. ${ }^{126}$ AuNPs, carbon-based NPs, polymeric NPs, and vesicular nanocarriers have the potential 
Table 3 Potential Nanobased Formulations for COVID-19 Treatment

\begin{tabular}{|c|c|c|c|c|}
\hline $\begin{array}{l}\text { S. } \\
\text { No }\end{array}$ & Nanoformulation & Features of the Nanoformulation & Reported Benefits of Nanoforms & Reference \\
\hline I. & $\begin{array}{l}\text { Dexamethasone } \\
\text { with } \\
\text { biomimetic NPs }\end{array}$ & $\begin{array}{l}\text { Encapsulating dexamethasone with leukocyte- } \\
\text { derived nanovesicles (leukosomes) }\end{array}$ & $\begin{array}{l}\text { - A significant survival advantage } \\
\text { - An improved immune response resolution } \\
\text { - Enhanced therapeutic activity of } \\
\text { dexamethasone }\end{array}$ & 113 \\
\hline 2. & $\begin{array}{l}\text { Inhalable liposomal } \\
\mathrm{HCQ}\end{array}$ & $\begin{array}{l}\mathrm{HCQ} \text { encapsulated in liposomes for inhalational } \\
\text { administration preparation }\end{array}$ & $\begin{array}{l}\text { - Improved pharmacokinetics } \\
\text { - Efficient aerosolized delivery } \\
\text { - Targeted antiviral levels with lower effective } \\
\text { - dose and less dosing frequency } \\
\text { - A sustained release } \\
\text { - Reduced systemic exposure }\end{array}$ & 114 \\
\hline 3. & $\begin{array}{l}\text { CQ/HCQ-coated } \\
\text { metallic NPs }\end{array}$ & $\begin{array}{l}\text { Adsorption of } \mathrm{HCQ} / \mathrm{CQ} \text { on } \\
\mathrm{Ag}, \mathrm{Au}, \mathrm{AgAu} \text { and } \mathrm{Pt} N \mathrm{NP} \text {. }\end{array}$ & $\begin{array}{l}\text { - Decreased side effects } \\
\text { - Low toxicity } \\
\text { - Improved antiviral activity }\end{array}$ & 115 \\
\hline 4. & $\begin{array}{l}\text { Liposomal } \\
\text { lactoferrin }\end{array}$ & $\begin{array}{l}\text { Lactoferrin (Lf), a multifunctional glycoprotein, } \\
\text { loaded in liposomes }\end{array}$ & $\begin{array}{l}* \text { Noninvasive oral and intra-nasal use } \\
* \text { Enhanced antiviral activity } \\
* \text { Under Phase } 2 \text { clinical trial }\end{array}$ & 116 \\
\hline 5. & Nanosponges & $\begin{array}{l}\text { Cellular nanosponges produced from human cell } \\
\text { membranes, attached with macrophages }\end{array}$ & $\begin{aligned}> & \text { Mimicked ACE-2, inhibit viral entry and } \\
& \text { attachment } \\
> & \text { SARS-CoV-2 is neutralized and unable to } \\
& \text { infect } \\
> & \text { Dose-dependent inhibition of the viral } \\
& \text { infectivity }\end{aligned}$ & 117 \\
\hline 6. & $\begin{array}{l}\text { Peptide } \\
\text { functionalized } \\
\text { AuNPs }\end{array}$ & The AuNP functionalized by new peptide & $\begin{array}{l}\text { o Forms the most stable complex with RBD. } \\
\text { o A great potential to inhibit the RBD of } \\
\text { SARS-CoV-2 } \\
\text { o Good antiviral agents against COVID-I9 }\end{array}$ & 118 \\
\hline 7.. & $\begin{array}{l}\text { Membrane-based } \\
\text { ACE2-Rich NPs }\end{array}$ & $\begin{array}{l}\text { Nanoparticles made from the } \\
\text { membranes of ACE2-rich cells }\end{array}$ & $\begin{array}{l}\checkmark \text { Prevented viral binding to host cells via } \\
\text { competitive inhibition } \\
\checkmark \text { Effective anti-SARS-CoV-2 } \\
\checkmark \text { Easy to produce }\end{array}$ & 119 \\
\hline 8. & $\begin{array}{l}\text { Liposomal } \\
\text { remdesivir }\end{array}$ & Aerosolized nanoliposomal carrier of remdesivir & $\begin{array}{l}\text { - Direct administration into the lungs. } \\
\text { - Drastically minimized side effects and } \\
\text { - enhanced efficacy } \\
\text { - Easy self-administration at home. } \\
\text { - An effective alternative for COVID-19 } \\
\text { treatment. }\end{array}$ & 120 \\
\hline
\end{tabular}

Abbreviations: ACE2, angiotensin converting enzyme-2; CQ, chloroquine; HCQ, hydrochloroquine; NP, nanoparticle; RBD, receptor-binding domain.

to induce cytokine and antibody responses which are dependent on their size, shape, and surface chemistry. By modifying these properties with respect to different targeting moieties, they can be promising strategies for targeted antigen delivery. ${ }^{127,128}$

\section{Nanobiomaterials}

Biomaterials are substances that are either formed by living organisms or extremely compatible by their nature. Novel biomaterials at their nanoscale level possess precise and effective drug delivery functions. ${ }^{129,130}$ Biomaterials are 


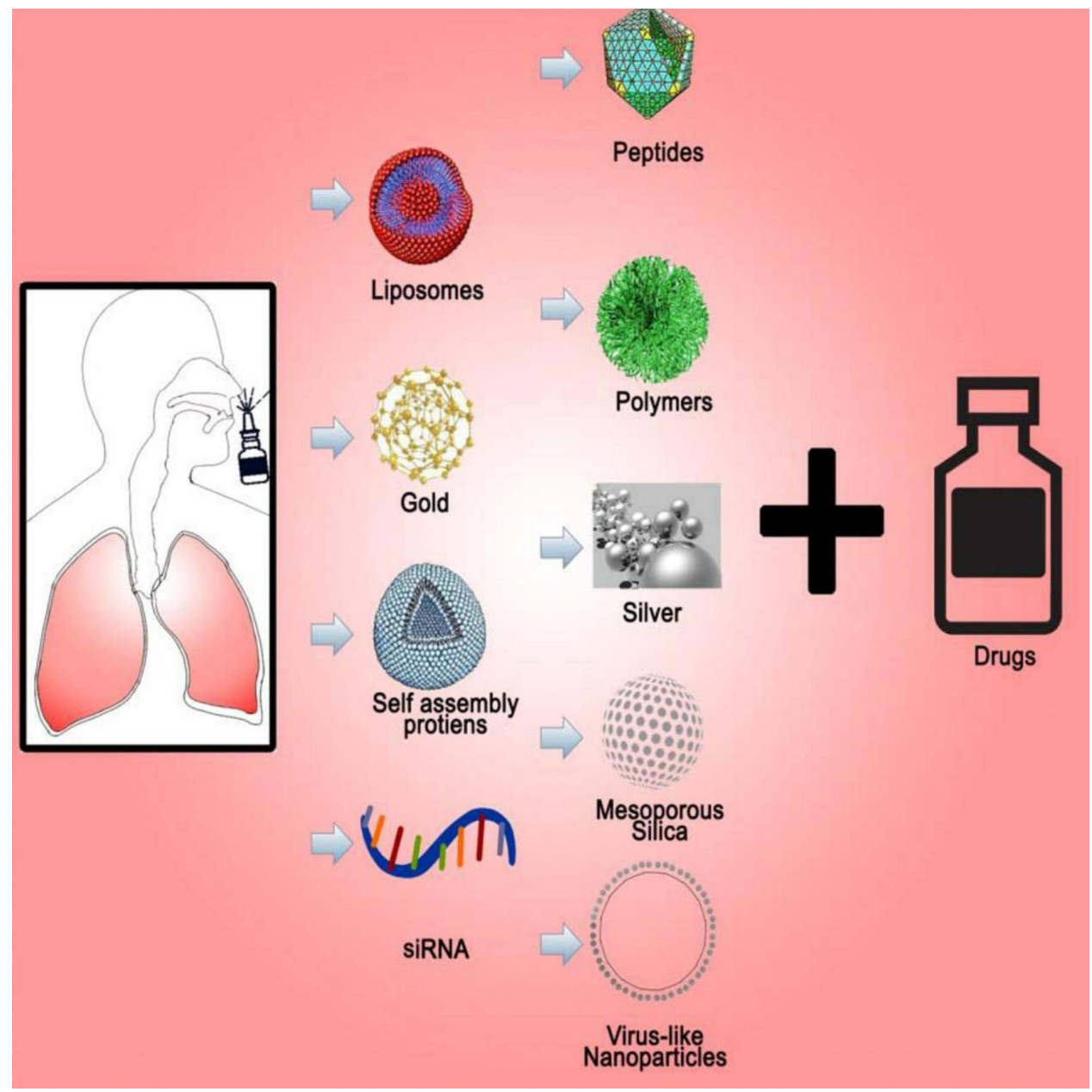

Figure 6 Intranasal nanodelivery for treating SARS-CoV2 infection. Copied from Nair SC, Joseph SK, Arya MK, Thomas S. State-of-the art nanotechnology-based drug delivery strategies to combat COVID-19. Int J App Pharm. 2021;13(3):18-29. doi: 10.22159/ijap.2021.v13i3.40865. ${ }^{121}$

reported for reducing mortality in COVID-19 patients. Investigations are being made with remarkable efforts to apply them in controlled delivery, for minimizing systemic administration complications, and alleviating disease severity. ${ }^{131}$ Bioengineered platforms of airway models are used to elucidate the pathophysiological processes of COVID-19 which is a rate-limiting step for management procedures and recommendations. ${ }^{132}$ Their biologic and physicochemical properties can be operated as to the different needs for therapeutic applications including the current pandemic. ${ }^{133}$ Tissue engineering and regenerative medicine are now providing promising solutions to viral outbreaks in diagnostics, treatment, vaccination, and surface disinfection which can be implied for their application toward COVID19. ${ }^{134}$ Organoids (clusters of organ-specific cells) were formed as effective models for COVID-19 viral examination. In addition, microfluidic organ-on-chip (OoC) systems have recapitulated host physiology, viral pathology, and therapeutic responses with high accuracy. ${ }^{135,136}$

Biomaterials have the potential to modulate the immune response, advance drug repurposing, and prevent or treat complications of COVID-19. ${ }^{137,138}$ Moreover, the nano-forms of biomaterials can improve quality of life by reducing the adverse effects of conventional therapeutics. Therefore, highly efficient, reliable, compatible, and recyclable biomaterial-based applications can support the fight against the current pandemic. ${ }^{46}$ Nanobiomaterial therapeutics can be used to deliver cargo directly to the respiratory targets (lungs) to avoid nontarget effects as they can be synthesized according to the ideal size range and controllable release for cellular targeting. ${ }^{139}$ Furthermore, many nanobiomaterials have intrinsic low cytotoxicity and high biocompatibility which are the currently needed essential attributes for COVID-19 
management. Nanobiomaterials in conjugation with Ag and mesoporous silica NPs could be used for the delivery of anti-inflammatory cytokines to counter the inflammation associated with COVID-19. ${ }^{138}$

Nanobiomaterial forms, such as gum-based hydrogels, nanogels, multilayered polyelectrolyte films, DNA aptamers, and nanocarriers like nanocapsules, nanospheres, and polymers demonstrated a potential effect that can add to the fight against COVID-19. ${ }^{22,126}$ Biomaterials in the form of nanoemulsions, nanodecoys, virus-like NPs (VLNPs) and self-assembly systems are being investigated and suggested for use against COVID-19. Nanoemulsions can easily transcytose lipophilic antigens across the intestinal cells. In addition, they can be synthesized with low cost and easy procedures; require easy storage conditions; demonstrate increased absorption rate and bioavailability; possess thermodynamic stability; provide solubility of lyophilic drugs, and improve the antiviral activity of the drug. ${ }^{140}$ Nanodecoys are cell membrane nanovesicles formulated to display high levels of ACE2 and cytokine receptors with the aim of competing for viral and cytokine binding. They can significantly inhibit SARS-CoV-2 replication and neutralize inflammatory cytokines. ${ }^{141}$ VLNPs are sphere-shaped NPs formed from several nanosized molecules and the self-assembly of viral proteins. They do not have genetic material content but structurally mimic the real virus enabling them to highly attract antigen-presenting cells and stimulate the immune response. ${ }^{105}$ Selfassembling NPs are excellent in carrying the drug, easily crossing the cell membranes, releasing drugs in a controllable manner at the target site, and synergistically activating the immune system. ${ }^{121}$

Nanobodies are other types of nanobiomaterials that can identify the pathogens, envelop the virus, and neutralize its functions. Hence, they can be diagnostic or therapeutic tools against the SARS-CoV-2 virus. $^{79}$ Researchers have isolated high stability nanobodies that can bind to spike protein of SARS-CoV-2, detect at an atomic level, and block the virus very specifically. ${ }^{142}$ The world's first humanized antibody against the SARS-CoV-2 inflammatory storm was discovered which can specifically damage the viral critical stage in the lungs. With little modification by using drug-loaded NPs, it can provide easy access for air sacs and blood vessels for free delivery of oxygen and blood. ${ }^{143}$ Cellular nanosponges made of the human plasma membrane epithelial type II cells or macrophages are reported as an effective countermeasure to SARS-CoV-2 since they display the same protein receptors required by SARS-CoV-2 for cellular entry. Therefore, they will neutralize and mutate SARS-CoV-2 making it unable to infect. ${ }^{117,136}$

Nanofibrous hybrids are active antiviral and antibacterial membranes that are formed embedded with AgNPs by an electrospinning process. They have subsequent screening with potential antiviral activities against different viruses, including SARS-Cov-2. They can also be applied in PPE and surface disinfection developments. ${ }^{144}$ Eco-friendly nonspherical nanocellulose nanofiber is synthesized which is a sustainable, nontoxic, low-cost, and biocompatible carrier with antimicrobial effects. ${ }^{145}$ Antibodies conjugated to biomaterial-based NP surfaces allow efficient and effective inflammatory marker removal caused by the cytokine storm. Chitosan, hyaluronic acid, PLGA, and mesoporous silica NPs can be used for surface conjugation to reduce the burden of SARS-CoV-2 cytokine storms. Ligand-based nanoparticulate biomaterials possess sequestration of cytokines and active-targeting for viral inactivation. The immune modulation effect of these systems can be assisted by codelivery of anti-inflammatory drugs. ${ }^{138}$

\section{Nanophytomedicines}

Nano-sized herbal medicines have been developed as nanophytomedicines based on their unique nature. Various nanotechnology-based systems such as polymeric NPs, solid lipid NPs, magnetic NPs, metal and inorganic NPs, nanospheres, nanocapsules, quantum dots, nanoemulsions, polymeric micelles, liposomes, and dendrimers have been tried for the successful delivery of natural products from traditional medicine. This brings potential herbal drug-loaded pharmaceutical carriers for alternative and complementary medicine to the modern system which can push the fight against many chronic and pandemic global issues like COVID-19 one step forward. ${ }^{146,147}$ Since the occurrence of COVID-19, diverse traditional medicines have been used alone or in combination with the conventional management systems. These herbal extracts may possess anti-SARS-CoV-2 actions by disrupting the viral life-cycle that can be a promising preventive and therapeutic alternative to the pandemic. ${ }^{148}$ In addition, their favorable oral stability and ease of scaling up make them ideal contenders for prophylactic and prevention strategies including vaccine development. ${ }^{149}$ Reports indicated that Chinese, Indonesian, and Nepalese people increased the use of medicinal plants during the COVID19 pandemic claiming that they can prevent or cure the disease and it is believed to have shown good results in 
fighting SARS-CoV-2 empirically. ${ }^{45,150-152}$ Adeleye et al, identified 15 potential ethnomedicinal herbs from different African countries for the discovery and development of therapeutic agents for COVID-19 applications. ${ }^{153}$ Phytotherapeutics has been recognized for its better therapeutics with fewer adverse effects than modern medicines. However, it needs a novel scientific approach for modified, sustained, and controlled delivery to enhance patient compliance and avoid repeated administrations. This can be achieved by designing nanostructured delivery systems and integrating them with nanocarrier approaches that can enhance its therapeutic activity while overcoming associated problems, such as bulk dosing and lower bioavailability. ${ }^{144}$

The sole combination between traditional medicine and nanomedicine will accompany a new era of affordable, safe, and effective medicinal systems that can be very supportive for a pandemic crisis like COVID-19. ${ }^{154}$ Plant metabolites and body parts of microorganisms can be delivered by spherical NPs as a potential strategy for antiviral therapies. ${ }^{145}$ Glycyrrhizic acid, a common ingredient in the Chinese herb licorice, has a known anti-SARS$\mathrm{CoV}$ effect, but its application is limited due to cytotoxicity, poor water and bio-fluid solubility, and low bioavailability. Synthesizing highly biocompatible glycyrrhizic acid NPs demonstrated a significantly enhanced antiviral and anti-inflammatory effects in vitro and in vivo. ${ }^{152} \mathrm{~A}$ typical Indonesian natural product administration culture, called jamu, is commonly practiced to relieve pain and inflammation from acute and chronic disorders. The efficacy and the value of jamu have been improved using various nanotechnology approaches such as nanosuspension, nanoemulsion, nanoencapsulation, and nanofiber fabrication. ${ }^{151}$ Researchers at Alfaisal University combined AgNPs with a black tea extract (theaflavin) and attained a potent viral replication inhibition effect that can assist in the fight against COVID-19 by slowing the viral reproduction rate in a host and reducing the severity of symptoms. $^{155}$

\section{Nanostructures for Postinfection Complications}

Nanostructures can also be used in the prevention of major organ complications, co-infections and postrecovery syndromes of COVID-19 infected patients. Antiviral nanobiomaterials, in the form of external vesicles, exosomes and artificial nerve conduits can cross the $\mathrm{BBB}$; promote synaptic plasticity; modulate immunity for poststroke pain and inflammation; facilitate neural regeneration, and treat neuropathies associated with COVID-19. ${ }^{56}$ Nanotargeting of cytokine receptors using lipid nanoemulsions demonstrated a promising application for minimizing dementia and brain inflammatory neurodegeneration which is a risk factor for Alzheimer's disease. ${ }^{156,157}$ The alarming rate of antimicrobial resistance with the upsetting emergence of new pathogens like SARS-CoV-2 will challenge the therapeutic approaches to many infectious diseases, which as a result, demand an accurate, fast, sensitive, specific, simple, and inexpensive diagnostics and therapeutics strategy. ${ }^{158} \mathrm{Ag}$, $\mathrm{Au}$, iron oxide, and titanium dioxide can be valuable NPs to combat secondary microbial infections and multidrug resistance in critically ill patients during COVID-19 infection which is known as "a silent risk". ${ }^{42,159}$ Furthermore, nanotechnology can help to address COVID-19-associated pneumonia by delivering anti-inflammatory nanodrugs and nanoantioxidants; providing inhalation methods; and utilizing oxygen-generation nanomaterials. ${ }^{160}$ Niclosamide-loaded albumin NPs, chitosan nanocarriers, biopolymer-derived nanocarriers, and lipid NPs demonstrated a highly viral entry inhibitory effect against SARS-CoV-2 in vitro and showed an extended circulating drug exposure in vivo, with a new, cheap, and scalable preparation process. ${ }^{161}$ In sum, all these nanotherapeutic strategies can provide timely solutions for combating the pandemic and open the door for future explorations.

\section{Nanovaccination}

Vaccines appear to be the preeminent solution in combating the pandemic even though their development, clinical trial processing, approval, and scale-up are time-consuming. But, investigations are being undertaken as quickly as possible. SARS-CoV-2 vaccine development is an the most astonishing one in history by getting into clinical trial phases within only three-to-six months which makes it the fastest of all the epidemics and pandemics. ${ }^{162}$ The application of nanomaterials in vaccine development and delivery has led to the birth of the concept of "nanovaccinology". NP-based vaccines with organic, inorganic, hollow polymeric, and biologic NPs possess potential benefits such as high payloads, tailorable size and surface properties, controllable and targeted release kinetics, improved stability, easy antigen uptake, and strong response induction. ${ }^{60,163}$ Nanobiomaterials can be vaccine adjuvants to enhance vaccine efficacy due to their lower systemic toxicity, stronger targeting, higher specific surface area, and lower immune titer. ${ }^{58,59}$ 
Subunit vaccines with NPs, such as virus-like proteins (VLPs) and protein NPs, are under active consideration in development processing. The receptor-binding domain (RBD)-based SARS-CoV vaccines are also considered as effective strategies. ${ }^{164}$ VLNPs are desirable NPs that stand out to cells that produce antigens; easily detect them, and stimulate an immune response. ${ }^{121}$ They can better be delivered through the lymph and capillaries, easily entering into the cell; reducing the systemic inflammatory response; increasing vaccine immunogenicity and efficacy; improving patient safety; and boosting the immune system. ${ }^{165,166}$ Nucleic acid-based vaccines demonstrated an enhanced delivery efficacy and stability when they are applied with cationic liposomes, dendrimers, and solid lipid NPs. ${ }^{167}$ Vaccines formulated with exosomal S protein of SARS-CoV resulted in induced and accelerated antibody neutralizing effect. ${ }^{168}$

NP-based inhalational vaccines provide high mucosal immunity in the lungs which are the main targets in respiratory infections like SARS-CoV-2. ${ }^{138}$ Intranasal vaccine delivery offers admirable safety, better convenience, both systemic and local immune response for controlling respiratory infections like SARS-CoV-2. ${ }^{169}$ PLGA NPs functionalized with ACE2 receptor proteins from alveolar epithelial cells and macrophages can neutralize viral infectivity. ${ }^{117}$ Extracellular vesicles containing ACE2 as decoys and ACE2 mRNA packaged with lipid NPs achieved a critical host mimicry to distract the host-binding ability of SARSCoV-2. ${ }^{170,171}$ Silica NPs coupled with polyethyleneimine showed easy trapping, protection, and delivery of DNA/ RNA antigens into cells with potential adjuvant effect, great loading capacity, robust bonding, and enhanced cellular uptake. ${ }^{136}$ Quantum dots (QDs), with much smaller sizes than the known NPs, have also shown a promising utilization for COVID-19 vaccine designing. ${ }^{172}$ Lipid-based NPs (LNPs) opened the way forward to COVID-19 and they are now considered as the frontrunner in nanoscale vaccine development and delivery. They promised for the potential success of mRNA-LNP vaccines and, therefore, a long journey of optimizing LNPs for nucleic acid-based delivery has been passed. ${ }^{173,174}$

NP-based vaccine development is now on the way in various pharmaceutical companies and research institutes. $^{175-177}$ Table 4 demonstrates some of the WHO-listed nanovaccines which are in clinical and preclinical phases. ${ }^{177}$

Most NPs for use in nanovaccines are known to be biodegradable, biocompatible, and less toxic and, therefore, they can be safe and effective alternatives to the conventional vaccines. However, nanovaccine-related side effects and safety concerns still remain to be investigated. ${ }^{178}$ Severe allergy-like reactions were reported from Pfizer and BioNTech novel vaccine products which is proposed to be due to nanopackaging compounds of the messenger RNA (mRNA). Polyethylene glycol (PEG) in vaccines may occasionally trigger anaphylaxis that causes a potentially lifethreatening reaction with complicated respiratory and cardiovascular disorders. ${ }^{179}$ LNPs in the Pfizer/BioNTech and Moderna vaccines' human trials demonstrated inflammation-like side effects such as pain, fever, swelling, and sleepiness. ${ }^{180,181}$ Oxidative stress, genotoxicity, hypercytokinemia, injection site inflammation, distribution, and persistence are also linked with nanovaccine toxicology. These side effects are probably associated with the antigen-NP, $\mathrm{NP}$-antigen presenting cell, NP-biosystem, and adjuvant-NP interactions. In the case of a pandemic crisis like the current one, risk is weighed against potential benefit for any new advance. ${ }^{182,183}$

\section{Nanopreventative Applications}

Nanomaterials can ultimately improve the COVID-19 prevention approaches by enhancing the surface disinfection, sanitization, and protective equipment efficiency and effectiveness as demonstrated by some investigation reports in Table 5. The use of nanomaterials in the production of PPE brings them new and improved properties in terms of resistance, efficacy, comfort and safety as summarized in Figure $7 .{ }^{129}$ The principles for the application of nanotechnology in COVID-19 prevention strategies are presented in the sections below.

\section{Nanotechnology-based Surface Disinfection}

Various chemical disinfectants are being applied widely in personal, household, and medical facilities for exhaustive sterilization during the pandemic. These include alcohols, phenol-based disinfectants, quaternary ammonium compounds, chlorine-releasing agents, iodophores, and highlevel disinfectants like formaldehyde. ${ }^{190}$ However, it is practically impossible to sanitize surfaces all the time, and there is no guarantee for the surface not to be recontaminated. ${ }^{9,191}$ Investigation is underway for smart surface coatings with inherent virucidal materials and selfdisinfecting abilities by the application of nanostructured techniques to surface disinfectants. ${ }^{68,69}$ These techniques include addition of intrinsic antiviral NPs, polymerization 
Table 4 Novel Nanostructured Vaccines for COVID-19 in Clinical and Preclinical Phases

\begin{tabular}{|c|c|c|c|c|}
\hline $\begin{array}{l}\text { S. } \\
\text { No }\end{array}$ & $\begin{array}{l}\text { Novel } \\
\text { Vaccine } \\
\text { Platform }\end{array}$ & Features of the Nanoformulation & Developer/Organization & Status \\
\hline I. & $\begin{array}{l}\text { Protein } \\
\text { subunit }\end{array}$ & $\begin{array}{l}\text { SARS-CoV-2 rS/Matrix MI-adjuvant (Full length recombinant SARS- } \\
\text { CoV-2 glycoprotein nanoparticle vaccine adjuvanted with Matrix M) }\end{array}$ & Novavax & $\begin{array}{l}\text { Clinical - } \\
\text { Phase } 3\end{array}$ \\
\hline 2. & $\begin{array}{l}\text { DNA-based } \\
\text { vaccine }\end{array}$ & $\begin{array}{l}\text { Covigenix VAX-00I - DNA vaccines + proteo-lipid vehicle (PLV) } \\
\text { formulation }\end{array}$ & Entos Pharmaceuticals Inc. & $\begin{array}{l}\text { Clinical - } \\
\text { Phase I }\end{array}$ \\
\hline 3. & $\begin{array}{l}\text { Protein } \\
\text { subunit }\end{array}$ & $\begin{array}{l}\text { Recombinant Sars-CoV-2 spike protein, Aluminum adjuvanted } \\
\text { (Nanocovax) }\end{array}$ & $\begin{array}{l}\text { Nanogen Pharmaceutical } \\
\text { Biotechnology }\end{array}$ & $\begin{array}{l}\text { Clinical - } \\
\text { Phase } 1 / 2\end{array}$ \\
\hline 4. & $\begin{array}{l}\text { Virus-like } \\
\text { particle }\end{array}$ & $\begin{array}{l}\text { An enveloped virus-like particle (eVLP) of SARS-CoV-2 spike (S) } \\
\text { glycoprotein and aluminum phosphate adjuvant. }\end{array}$ & VBI Vaccines Inc. & $\begin{array}{l}\text { Clinical - } \\
\text { Phase } 1 / 2\end{array}$ \\
\hline 5. & $\begin{array}{l}\text { RNA-based } \\
\text { vaccine }\end{array}$ & Self-replicating mRNA vaccine formulated as a lipid nanoparticle (LNP). & SENAI CIMATEC & $\begin{array}{l}\text { Clinical } \\
\text {-Phase I }\end{array}$ \\
\hline 6. & $\begin{array}{l}\text { DNA-based } \\
\text { vaccine }\end{array}$ & Plasmid DNA, nanostructured RBD & $\begin{array}{l}\text { National Institute of Chemistry, } \\
\text { Slovenia }\end{array}$ & Preclinical \\
\hline 7. & $\begin{array}{l}\text { Viral vector } \\
\text { (non- } \\
\text { replicating) }\end{array}$ & Lentiviral vector retro-VLP particles & Sorbonne University & Preclinical \\
\hline 8. & $\begin{array}{l}\text { Protein } \\
\text { subunit }\end{array}$ & RBD protein delivered in mannose-conjugated chitosan NP & $\begin{array}{l}\text { Ohio State University/Kazakh } \\
\text { National Agrarian University }\end{array}$ & Preclinical \\
\hline 9. & $\begin{array}{l}\text { Protein } \\
\text { subunit }\end{array}$ & S subunit intranasal liposomal formulation. & University of Virginia & Preclinical \\
\hline 10. & $\begin{array}{l}\text { Protein } \\
\text { subunit }\end{array}$ & $\begin{array}{l}\text { Recombinant protein, nanoparticles (based on S-protein and other } \\
\text { epitopes) }\end{array}$ & $\begin{array}{l}\text { Saint-Petersburg Scientific } \\
\text { Research Institute of Vaccines and } \\
\text { Serums }\end{array}$ & Preclinical \\
\hline II. & $\begin{array}{l}\text { RNA-based } \\
\text { vaccine }\end{array}$ & LNP-encapsulated mRNA cocktail encoding VLP & $\begin{array}{l}\text { Fudan University/ Shanghai } \\
\text { JiaoTong University/RNACure } \\
\text { Biopharma }\end{array}$ & Preclinical \\
\hline 12. & $\begin{array}{l}\text { RNA-based } \\
\text { vaccine }\end{array}$ & Liposome-encapsulated mRNA & BIOCAD & Preclinical \\
\hline 13. & $\begin{array}{l}\text { RNA-based } \\
\text { vaccine }\end{array}$ & $\begin{array}{l}\text { A self-amplifying RNA vaccine encapsulated in an LNP, which encodes } \\
\text { for multiple antigens, including the spike (S) protein }\end{array}$ & $\begin{array}{l}\text { Ziphius Vaccines and Ghent } \\
\text { University }\end{array}$ & Preclinical \\
\hline
\end{tabular}

Abbreviations: LNP, lipid nanoparticle; RBD, receptor-binding domain; VLP, virus-like particle.

with intrinsically pathogen-resistant nanomaterials, metallic surface coatings, and nanotexturing. ${ }^{192}$

Various metal and metal oxide NPs such as AuNPs, AgNPs, ZnONPs, CuONPs, SiONPs, nanosized copper (I) iodide NPs (CuINPs), and quaternary ammonium cations commonly (QUATs) are capable of inactivating virus from surfaces. ${ }^{9}$ Metallic NP-based disinfectants have interesting features in terms of fabrication process and cost, safety and toxicity, life-span, antiviral activity, eco-friendliness, nonirritating, and nonfoaming properties to protect the pandemic viral transmission. ${ }^{19}$ They can be synthesized using the green synthesis approach from natural resources such as plant parts, insects, and animals. They provide an adsorbent property by their larger effective surface area, and a controlled release of the disinfectant molecules. ${ }^{193,194}$ They can be used for coating surfaces to oxidize and release ions with antimicrobial properties for disinfection. Controlled and sustained ion diffusion from metals like $\mathrm{Cu}$ modulates antiviral characteristics of surfaces. ${ }^{195}$ In addition; they are dermatologically safe and excellent in 
Table 5 Nanobased Protective Equipment for COVID- 19 Prevention

\begin{tabular}{|c|c|c|c|c|}
\hline $\begin{array}{l}\text { S. } \\
\text { No }\end{array}$ & $\begin{array}{l}\text { NanoBased } \\
\text { PPEs }\end{array}$ & Features of the Formulation & $\begin{array}{l}\text { Reported Benefits of Nanobased } \\
\text { PPE }\end{array}$ & Reference \\
\hline $\mathbf{I}$ & $\begin{array}{l}\text { Ag nanocluster/ } \\
\text { silica } \\
\text { composite facial } \\
\text { masks }\end{array}$ & $\begin{array}{l}\text { - Silver nanocluster/silicacomposite coating deposited on } \\
\text { impregnated in facial masks }\end{array}$ & $\begin{array}{l}\text { - Promising virucidal property, } \\
\text { - Enhanced SARS-CoV-2 titer } \\
\text { reduction, } \\
\text { - Great safety to be used in crowded } \\
\text { areas } \\
\text { - Increased working life of filtering } \\
\text { masks } \\
\text { - Reduced waste production }\end{array}$ & 184 \\
\hline 2 & $\begin{array}{l}\text { Metal oxide nano- } \\
\text { compounded hand } \\
\text { sanitizer }\end{array}$ & $\begin{array}{l}\text { - Nonalcohol-based neosporin, muprocin, and tetracycline } \\
\text { NPs blended with soap solution sanitizers }\end{array}$ & $\begin{array}{l}\text { - Impart effective antiviral activity } \\
\text { - Skin-friendly hand sanitizers }\end{array}$ & 185 \\
\hline 3 & $\begin{array}{l}\text { Zinc oxide } \\
\text { nanospray }\end{array}$ & $\begin{array}{l}\text { - Zinc (II) oxide NP (ZnO-NPs) used as a disinfectant } \\
\text { nanospray }\end{array}$ & $\begin{array}{l}\text { - High anti-SARS-CoV-2 activity at } \\
\text { cytotoxic } \\
\text { - Reduced host cellular toxicity } \\
\text { - Elevated antiviral activity against } \\
\text { SARS-CoV-2 }\end{array}$ & 186 \\
\hline 4 & $\begin{array}{l}\text { Silver NP (AgNPs)- } \\
\text { based } \\
\text { surgical masks }\end{array}$ & - Surgical masks by impregnating AgNPs & $\begin{array}{l}\text { - Superior microbial reduction of } \\
99.999 \% \text { against a wide number of } \\
\text { microorganisms. } \\
\text { - Reusing surgical masks } \\
\text { - Effective decontamination }\end{array}$ & 187 \\
\hline 5 & $\begin{array}{l}\text { Graphene nano } \\
\text { based } \\
\text { PPEs }\end{array}$ & - Coating onto fabrics such as face masks and gloves & $\begin{array}{l}\text { - Excellent antimicrobial efficacy, } \\
\text { - Providing both physical and chemi- } \\
\text { cal mechanisms of damage }\end{array}$ & 188 \\
\hline 6 & $\begin{array}{l}\text { Nanofiber } \\
\text { membrane } \\
\text { reusable masks }\end{array}$ & $\begin{array}{l}\text { - Masks fabricated by melt blown fabrics and nanofiber mem- } \\
\text { brane from spider-web bionic nanofiber membrane (nano- } \\
\text { cobweb-biomimetic membrane) }\end{array}$ & $\begin{array}{l}\text { - Achieved the disinfection and reuse } \\
\text { of masks } \\
\text { - Can effectively alleviate the short- } \\
\text { age of masks } \\
\text { - Better repeatability and disinfection } \\
\text { tolerance } \\
\text { - High aerosol rejection efficiency }\end{array}$ & 189 \\
\hline
\end{tabular}

keeping public places safer from COVID-19 risks. ${ }^{15}$ Surfaces can be coated by nanopolymers in different ways. First, with a simple drop-casting method, a polymer solution will be dropped to coat the surfaces and then allowed to evaporate. In the second method, a dip coating technique can be done by immersing a substrate in the polymer solution, with consequent withdrawing, evaporation and drying. In a cast-coating technique, the polymeric solution will be cast onto the surface followed by solvent evaporation. $^{196}$

Surfactant-coated NPs provide special antistatic, stabilizing, antiviral coating properties for surface disinfection. ${ }^{108}$
Apart from coatings, NPs like AgNPs demonstrated antiviral effects including SARS-CoV-2 when applied in their nanopowder forms, which can also be applicable for face masks and air filters. ${ }^{197,198}$ Copper NPs had been proven for theirs antiviral effect against HCoVs by degrading and inactivating the viral genome which may be projected for use against the current pandemic, SARS-CoV-2. ${ }^{199}$ Recent studies also reported that CuNP-loaded surfaces can easily deactivate SARS-CoV-2 and be developed with less economy than AgNPs and with excellent stability. ${ }^{200,201}$ Furthermore, conjugation of CuNPs with quaternary ammonium structures exhibited enhanced antiviral activity. ${ }^{202}$ Replacing plastic and stainless steel materials with $\mathrm{Cu}$ alloy can limit COVID-19 


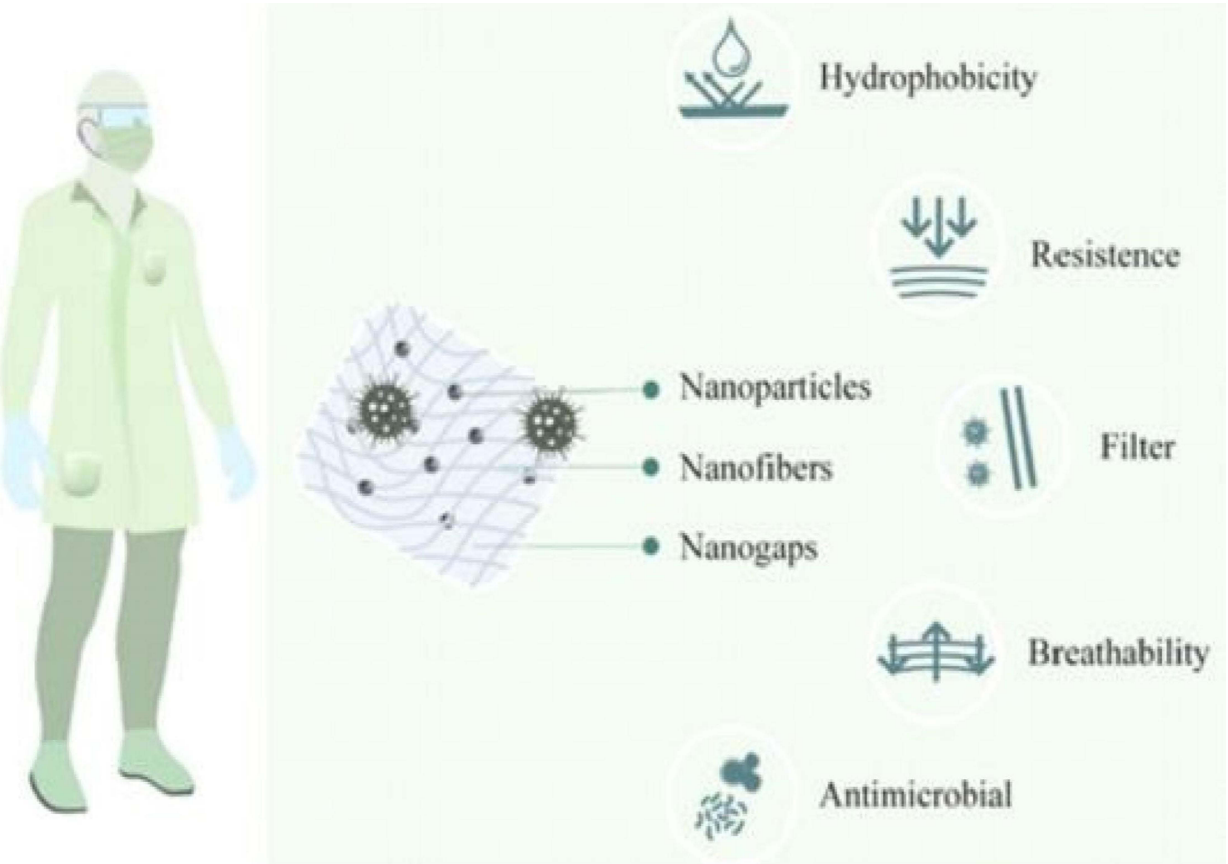

Figure 7 Nanotechnology applications for production of PPE against COVID- 19. Copied from Campos EVR, Pereira EAS, de Oliveira JJ, et al. How can nanotechnology help to combat COVID-19? Opportunities and current need. J Nanobiotechnol. 2020;18:125. doi: I0.1 I86/s | 295।-020-00685-4. ${ }^{129}$

spreading on surfaces. ${ }^{203}$ In another way, photothermal inactivation of SARS-CoV-2 from surfaces can be done by illuminating $\mathrm{Ag}$ and $\mathrm{Au}$ NPs and nanorods at an optimal wavelength to induce heating for viral inactivation. ${ }^{204}$ Encapsulating objects with photoactive nanomaterials and using electromagnetic radiation to disrupt SARS-CoV-2 cells are other methods for surface disinfection. ${ }^{205}$

A study done by Abo-zeid et al showed that iron oxide NPs, both $\mathrm{Fe}_{2} \mathrm{O}_{3}$ and $\mathrm{Fe}_{3} \mathrm{O}_{4}$, can interact with viral spike protein destroying its ability of host cell attachment. In addition, they produced reactive oxygen specious (ROS) that inactivates SARS-CoV-2 in surfaces. ${ }^{206}$ Titanium dioxide $\left(\mathrm{TiO}_{2}\right)$ nanocoating is the other alternative for sanitizing public utilities and mass gathering areas. Due to its UV induced photocatalytic properties, it has an effective multidimensional application for decontaminating and minimizing the COVID-19 transmission. It is a convenient and cost-effect disinfecting approach, even for remote locations, through $\mathrm{TiO}_{2}$-doped paints, air filtration aerosolized filters, $\mathrm{TiO}_{2}$-impregnated ventilation systems, and $\mathrm{Cu}$ and Ag-loaded $\mathrm{TiO}_{2}$ nanowires. Surfaces coated with aluminum alloy NPs also demonstrated an effective SARS-CoV-2 disinfection within six hours. ${ }^{207,208}$

Physicochemical properties of graphene nanomaterials can be used to control the transmission of the COVID-19 pandemic by deactivating the virus from surfaces.
Graphene and its derivatives inactivate the virus by exerting photothermal activities and binding to the viral $\mathrm{S}$ protein that results in inhibition of cellular interactions to the host cell receptors. ${ }^{25,209}$ Water treatment using nanostructures of light-activated, layered graphitic carbon nitride disables the contaminating ability of viruses including SARS-CoV-2. ${ }^{79}$ Nanostructured anionic polymers showed $\mathrm{pH}$ adjusted, rapid and continuous disinfecting ability which can be a good alternative to inactivate the virus in a self-disinfecting manner. ${ }^{210}$ In recent times, nanobased air ionizers and surface purifiers that can be applied for decontaminating buildings and public offices are being studied and developed. ${ }^{211}$ Polymers can be awarded an antimicrobial effectiveness by covalent conjugation of biocidal agents such as quaternary ammoniums, phosphonium groups, chlorine dioxide, alcohols, and sulfonates to produce permanently coated, nonleaching sterile surfaces. ${ }^{125}$ Ventilator units can also be coated with the same principles to reduce the likelihood of COVID-19 infection and cross-infections. ${ }^{19}$

\section{Nanotechnology for Improvement of Personal Protection Equipment (PPE)}

PPE includes textile materials such as headgear, goggles, masks, gloves, facial protection, and dresses or gowns. They are critical elements for protection from COVID-19 
transmission. Nanostructures used in PPE modification are responsible to adsorb viral particles for viral inactivation and filtration efficiency which is the main principle for their application of COVID-19 prevention. $^{212}$ The main challenges encountered by conventional PPE are associated with their poor antitoxicity, difficulty in breathability, heat dissipation, and reusability. ${ }^{176}$ Uncertainties are also rising on which, how, and how much they permit COVID-19 transmitability, especially in workplace settings and densely populated gathering areas which necessitates more trustworthy, cost-effective, efficient, and reusable PPE development. ${ }^{213}$ Appropriate understanding of the role and the usage of PPE by the health staff and the public and ensuring an adequate supply system are considerable factors for imminent prevention of the pandemic. That is why their application worldwide has not been enough to stop the transmission. ${ }^{63,64}$

Environmental safety and waste management is another complicated issue during the pandemic season. It puts a substantial burden and results in a health compromising situation including carcinogenic health impacts questioning for other alternative technologies for the production of biomedical equipments and treatment of COVID-19 related wastes. ${ }^{65,66}$ Moreover, single-use PPE types become factors in environmental pollution and sources of biohazards. Not only the discarded PPEs, but also their derived decomposition products are threatening the aquatic organisms and human life that may persist for many years in the future. ${ }^{67-69}$ Hasan et al revealed the potential long-term effects of these environmental impacts on aquatic ecosystems and human health as: physical effects (changes in microbiome, water quality deterioration, ecosystem alteration), physiological effects (reproduction hamper, oxidative stress, decreased survival, metabolic damages), long-term effects (immunosuppression, carcinogenicity, geno-toxicity, neurotoxicity). ${ }^{70}$ This indicates that advanced technologies for the development of eco-design approaches for PPE production are needed. $^{71}$

Nanostructures can impart their role by reducing single-use PPE by replacing them with novel reusable, selfcleaning, effective, and efficient antiviral products to minimize environmental challenges. This can be brought about by the application of antiviral NPs, nanofibers, and NPcoatings to acquire super-hydrophobicity, synergistic effects, self-cleaning functionalities with photothermal and photocatalytic sterilization. ${ }^{72,214}$ For these purposes, nanomaterials with intrinsic antiviral activity, such as
AgNPs, graphene oxide (GO), CuO NPs, two-dimensional carbides, and nitrides that can capture and inactivate viruses are being investigated. ${ }^{176,215}$ Furthermore, a fluorescent NP penetrant inspection can be used for the detection of inner defects in used masks, to provide necessary data for the development of reusable masks, structural optimization, and evaluation standards. ${ }^{216}$ Less material consumption and reduced supply problems, efficient filtration due to large surface areas, cost-effective transmission control, and virus neutralization due to functionalization with chemically active groups are the main features of PPE modifications by using nanomaterials and nanotechnology. $^{217}$

Size- and time-dependent particle removal efficiency is reported from different protective respiratory masks which can be optimized by nanostructured systems. ${ }^{218} \mathrm{Ag}$ nanocluster/silica composite nanocoating impregnated in facial masks possessed a promising virucidal property, reduced the SARSCoV-2 titer, and provided great safety to be used in crowded areas. ${ }^{178}$ In addition, $\mathrm{SiO}_{2}$ and $\mathrm{Al}_{2} \mathrm{O}_{3}$ NPs coated with polypropylene or polyethylene demonstrated super water repellent effects; $\mathrm{TiO}_{2}$ and $\mathrm{MgO} \mathrm{NP}$ coatings provided self-sterilizing activity; indium-tin oxide NPs produced an electromagnetic/ infrared protective clothing and ceramic NPs resulted in an increased abrasion resistance. ${ }^{219,220}$ Generally, the mechanisms in these NP coating effects are reported to be surface oxidation, releasing free radicals or toxic ions, ROS generation, photoreaction, inhibition of viral interaction, entry and binding. ${ }^{221}$ Nanotechnology can also increase the filtration efficiency through improving viral particle capturing and retention, enabling rapid viral inactivation after capturing them, minimizing exhaled humidity effects on particle redistribution, and providing a very thin, high-efficiency reusable filtration media. ${ }^{61}$

The application of nanofiber technology for face masks can reduce breathing resistance, maximize comfort by minimizing pressure, and provide enhanced filtration efficiency against very small viral particles $(<50 \mathrm{~nm}){ }^{22}$ The Egyptians discovered a novel, reusable, recyclable, customizable, antimicrobial, and antiviral respirator facial mask feasible for mass production. The novel design is based on the filtration system composed of a nanofibrous matrix of polylactic acid and cellulose acetate containing $\mathrm{CuO}$ NPs and GO nanosheets produced by electrospinning technique. ${ }^{222}$ Nanofiber filter incorporated surgical masks showed a decrease in air-flow resistance, improved filtration efficiency, enhanced contaminant deactivation, and reduced risk of inhaling pathogens. ${ }^{223}$ Similarly, other PPE like gowns, facial shields, gloves, boots, and goggles can be 
advanced with the aid of efficient and multifunctional nanostructures. ${ }^{61,79}$

\section{Pharmacoeconomic and Regulatory Aspects}

In the clinical trial of the COVID-19 vaccine, the two lipid mRNA-based vaccines, BNT162b2 and mRNA-1273, exhibited more than $95 \%$ efficacy, owing to their unique nanocarrier characteristics. $^{224}$ Even though such effectiveness with reduced medicine intake and adverse effects can be achieved with nanomedicine, there is still a substantial concern on their toxicity. Moreover, the development of these nanostructured systems should be regulated as all marketing items must follow regulatory requirements. ${ }^{225,226}$ There is an international debate on the risk regulation of NPs. To resolve this controversy, uniform definitions of NPs are required for the identification and application of legal provisions to them and facilitate the marketing of nanotechnology-derived products. There should also be a validated method of analysis, detection, characterization, and complete information regarding the impact of nanomaterials as well as the assessment of nanomaterial exposure. ${ }^{227,228}$ The use of nanotechnology may result in significant problems, causing irreversible damage to the environment and humans, if adequate rules and legislation are not in place. $^{229}$ The legal framework of nanotechnology was investigated to see if new regulatory action was necessary to address the hazards associated with nanomaterials. To take advantage from the benefits of nanoproducts, especially in severe pandemics like COVID-19, the public, customers, and employees need flexible and balanced regulatory actions based on scientific data. In addition, development of standards and guidelines on their preparation and use should be outlined to ensure safety and reduce the risk of liability. ${ }^{230}$

Authorization of substances and ingredients, qualification of hazardous waste, reinforcing conformity assessment methods, and restrictions on the entry of chemical substances and preparations to the market as well as their usage are all part of the nanomaterials regulation. ${ }^{227,230}$ Current regulatory frameworks cover a wide range of products and processes, including nanotechnologies, which implies that a separate regulator or regulatory framework may be unnecessary. However, some case studies suggest that the present framework should be modified because of the strange and uniqueness of NPs. ${ }^{230-232}$ Recent discoveries such as the NPbased COVID-19 vaccines, diagnostic, and therapeutic agents as well as PPE are now coming to support the globe's fight against the pandemic. However, current regulations may not be sufficient to solve their risk management, production challenges, and market issues which necessitate working more on the nanoregulatory issues parallel to nanoproduct discoveries. $^{228}$ Lack of understanding and communication about the science, use, and regulation of nanotechnology among all stakeholders hurts society perceptions and regulatory decision-making. ${ }^{233}$ Even though the risks posed by nanomaterials to the environment and humans have become a global concern, it is recommended for all relevant regulatory bodies to consider the impact of NPs in protecting humans from current and future pandemics such as COVID-19. ${ }^{234}$

Regarding the pharmacoeconomic aspects, there is a debate on the economic influence of nanotechnology. Reports are indicating that its short-term effect is minor, but it will provide a substantial economic impact in the long-term. Its prospective economic effects will be fully beneficial across the society and the spectrum of developed and developing countries. There was no evidence that nanotechnologies generate economic challenges that were notably different from those raised by other technological advancements. ${ }^{230,235}$ However, certain studies predicted that nanotechnologies can offer economic benefits, including the ability to create jobs, wealth, and wellbeing. $^{236}$ These technologies are also shown to be a costeffective option for many challenging medicine approaches. $^{229}$ A pharmacoeconomic study would allow for the most efficient use of monetary resources and the maximum health return at the lowest possible cost. The high failure rate for innovative therapeutic compounds in the drug development cycle is mostly attributable to economic considerations to save resources. ${ }^{237}$ Such costbased approaches have a significant impact on the development of nanotechnology-derived products and management strategies against the COVID-19 pandemic. $^{224}$

Nanomedicines have the potential to make a significant contribution to inexpensive health care, but a rigorous evaluation through updated cost-effectiveness evaluations is required first. In global pandemic challenges, like the current COVID19 pandemic, the success of introducing highly-priced and efficacious, yet costly, nanotherapies to market with their affordability can be considerably improved by using specific decision-making frameworks. The implementation of comprehensive, standardized cost-effectiveness studies can shift the focus to reducing health-care costs while maintaining care quality. One major flaw in current cost-effectiveness research in the field of nanomedicine is that, practically all studies focus solely on direct treatment costs, completely ignoring indirect 
costs. $^{238-240}$ This concern may highly challenge the applicability of nanomaterials and their support on combating COVID19 by the time the conventional approaches and repurposing strategies are unable to retard and resist its drastic global transmission. Conversely, nanomedicine has the potential to save health-care expenses by reducing treatment costs through focused therapy, reducing hospital stays, promoting healthy aging, and focusing on chronic diseases. ${ }^{241}$ This confirmed that the importance of nanotechnology in the COVID-19 vaccination and treatment will be uncountable, as COVID-19 is associated with various organ complications, needs targeted therapies, and results in chronic postinfection syndromes. ${ }^{242}$

\section{Current Outcomes, Challenges, and Future Perspectives: Summary Valuable Outcomes \\ Advanced Products}

Advanced vaccines, PPE, disinfectants, surface coatings, nanobased sensors, and therapeutic agents that will improve treatment success rates are now coming forward to the laboratories, clinical trials, and are even in the market. ${ }^{140,243}$ Simple, lowcost procedures for low-resourced medical infrastructures and less-developed nations will be the main benefiting outcomes from these nano-advanced products. ${ }^{88,92}$ Broad-spectrum antiviral nanodrug or functionalized biocompatible NPs have been synthesized which irreversibly and permanently inhibit the virion preventing the re-replication inside the host. ${ }^{244}$ Antiviral drugs and nanovaccines with lung targeting, superior circulation and retention time, remote loading, decreased systemic immunotoxicity, prodrug forms of controlled and localized release, reduced dosage, combination therapeutics, lowered dose and toxicity, and augmented cellular uptake are also reported positive outcomes. ${ }^{245}$

\section{Bionanotechnology and Nanomedicine}

Connecting the biomaterial science, nanotechnology, and medicine offered novel and smart nanodelivery systems with effective prevention, efficient diagnostics, and higher efficacy therapeutics. These systems can potentially counter challenges related to site-specific delivery, controlled release and maintenance of stability which will be extremely vital in fighting the COVID-19 pandemic outbreak. ${ }^{95}$ A nanobased vaccine (mRNA-LNP) for SARS-CoV-2 is being developed and found to be successful. The utilization of nanobiomaterials for COVID-19 vaccine and therapeutics development promised more potent and versatile applications. ${ }^{246}$

\section{Research and Patents}

Despite persisting for a very short time, there are many new investigations and patents related to COVID-19. From these patents, more than $10 \%$ are associated with "nano" topics including the use of different nanostructured systems for diagnostic, therapeutics, vaccination, and preventive approaches as nanocarriers, vectors, markers, filters, adjuvants, and intrinsic antimicrobials. ${ }^{125,247}$ Research and development is still underway on the effective application of nanomedicine with industrial implications to enhance safety, high sterilization capability with a low dosage, reusability, and eco- and user-friendly properties. ${ }^{19,188}$ Efficiently targeting antiviral nanocarriers and personalized therapy with precision nanomedicine are the near future perspectives of such investigations. ${ }^{9}$

In summary, COVID-19 management can benefit from nanostructured delivery systems in that it can potentiate immune response modulations which may otherwise be difficult conventionally, possess precise targeting, reduce nontarget accumulation and associated toxicities, protect drugs and vaccines from degradation and inactivation in body environment, offer alternative vaccine delivery routes, and possess promising biodegradability and biocompatibility that can be controlled. ${ }^{248}$

\section{Limitations and Challenges Clinical Extrapolation}

With those vast advantageous outcomes, clinical translation of the nanoproducts has not yet been achieved. Unpredictable side effects, safety, and toxicity concerns, long-term fate, cost and complexity of NP preparations, need for pure study designs with acceptable sample sizes and validated methods are the persisting challenges. ${ }^{138,139}$ In contrast there are also probable limitations of the promising advantages of nanoformulations including difficulty to sterilize parenteral formulations suitably, biomolecule denaturation risks, low entrapment efficiencies, biodistribution profile characterization, off-target accumulations, and uncontrollable burst release effects. ${ }^{22}$

\section{Disease and Pathogen Characterization}

The other vital issue is the lack of deepest understanding of the cellular, pathogenic and pathophysiologic aspects of SARS-CoV-2 and COVID-19 with the particular nanobiointerfaces involved in drug/vaccine development and delivery. ${ }^{8}$ SARS-CoV-2 also revealed different behaviors in different hosts which entails the need for the design of highly efficient nanosystems such as biomimetic organoids and organ-onchips that can specifically assess and evaluate these behavioral variabilities. ${ }^{135}$ Even though the lungs are the best 
targets in COVID-19 management, direct and targeted intranasal and pulmonary nanodeliveries are associated with severe impairment in respiratory sites and lung function. Further proof is needed to assure nanomaterial safety related to intolerable inflammation, cellular damage, fibrosis, small granulomatous lesions, geno-immunotoxicity, and oxidative stress due to abnormal NP accumulation in the alveoli which results in alveolar cell damage, blood vessel penetration, and then translocation to other organs..$^{249-251}$ The design of such nanocarriers in such a way that the nanoformulation can escape the recognition by scavenger cells is also challenging and needs considerable effort before clinical translation. ${ }^{61}$

\section{Large-scale Production}

Scaling up, complicated fabrication process and only limited information on how and how much the NPs exert their impact on organisms with peoples' reluctance to accept new technologies are other reported challenges. ${ }^{111}$

\section{Regulation}

Patent and intellectual property right issues remained challenging through this global pandemic era. The Open COVID Pledge requests patent and intellectual proprietors to voluntarily sacrifice the rights in helping the free fight during the crisis, but it is still being debated as it is dependent on the willingness of the patent holders. ${ }^{219}$ Moreover, regulatory issues are still far-away for the confidential application of nanomedicine with its full potentials. Ethical, scientific, biosafety and acceptance issues by regulatory agencies hinder nanomedicine to produce safe and high-quality nanodrugs including antivirals of this pandemic. .,135 $^{9}$

\section{Future Perspectives}

\section{Concerned Effort from the Pharmaceutical World}

Having the opportunities and the challenges from nanotechnology, nanomedicine, and biotechnology in mind, the pharmaceutical society must put endless effort on investigating nanotherapies to manage COVID-19. Here, from the pharmaceutical point of view, searching for better antimicrobial/antiviral therapeutic agents with better efficacy and minimized adverse effects, optimizing dosages, and delivery systems for carriers and targets, investigating biocompatible, bio-functionalized, nanodrug loading systems; designing stimuli-responsive, immunosupportive, and immunomodulating agents by using nanopharmacology concepts, and developing personalized nanotherapeutics are based on variations of the effects of SARS-CoV-2 and patient-specific disease profiles. ${ }^{82}$

\section{Multidisciplinary Research}

The current pandemic crisis can be taken as a golden opportunity for the transformation of nanomedicine by intensifying the safety to risk ratio of nanostructures. For this to be true, in-depth investigational study, experiencesharing, and exchange of knowledge among different countries, different departments, and different companies including regulatory agencies are essential. ${ }^{9,176}$ Early stage regulatory guidelines with a mid and long-term research on positive opportunities and about factors that limit their applicability are needed. This can enable the global medical practice against the current and future pandemics. ${ }^{46}$

\section{Combination of Technologies}

Nanomedicine is now trying to combine the advance from machine learning, artificial intelligence (AI), and internet of medical things (IoMT) for modeling, encoding and interpreting cell-nanomaterial interactions which is crucial to forecast biosafety, predict efficacy, and formulate quantitative nanostructure activity-relationship (nano-QSAR). These combined applications can support the global struggle against COVID19 by providing simplified data collection, mobile-sensing, as well as self-sampling of COVID-19 tests. Other related technologies such as robotics, telemedicine and 3D-printing can further complement the effective application of nanomedicine in fighting the pandemic. ${ }^{108,252}$

\section{Conclusion}

Even though the COVID pandemic is accelerating globally, there are still no approved drugs and internationally accepted free-access vaccines to counter its worldwide spread. Accurate prevention, rapid and early detection, effective immunomodulation, and definitive treatment strategies are not yet outlined. Nanostructured drug development and delivery-based research and development is now promising the world to end the pandemic effectively and shortly with radically modified therapeutic, diagnostic and prevention options. Should all regulatory, scale-up, and safety issues be settled, nanotechnology can guarantee the world for the current and the next unpredictable pandemic crisis. Extensive scientific research and collaborative multidisciplinary efforts are needed for its practically extrapolatable outcome.

\section{Abbreviations}

ACE2, angiotensin converting enzyme-2; BBB, bloodbrain barrier; CNS, central nervous system; COVID-19, coronavirus disease-2019; CPT, convalescent plasma therapy; CQ, chloroquine; DNA, deoxyribonucleic acid; 
$\mathrm{HCoV}$, human corona viruses; HCQ, hydroxychloroquine; IL, interleukin; LNP, lipid nanoparticle; NP, nanoparticle; PCR, polymerase chain reaction; PLGA, poly lactic-coglycolic acid; POC(D/T), point-of-care (diagnosis/testing); PPE, personal protective equipment; RBD, receptor-binding domain; ROS, reactive oxygen specious; RNA, ribonucleic acid; S, spike; SARS-CoV-2, severe acute respiratory syndrome - coronavirus - 2; VLNP, viruslike nanoparticle; VLP, virus-like protein; WHO, World Health Organization.

\section{Acknowledgments}

Addis Ababa University and Bahir Dar University are thankfully acknowledged for giving us internet access.

\section{Author Contributions}

All authors made a significant contribution to the work reported, whether that is in the conception, execution, acquisition of data, analysis and interpretation, or in all these areas; took part in drafting, revising or critically reviewing the article; gave final approval of the version to be published; have agreed on the journal to which the article has been submitted; and agreed to be accountable for all aspects of the work.

\section{Disclosure}

The authors report no conflicts of interest in this work.

\section{References}

1. Wang C, Horby PW, Hayden FG, Gao GF. A novel coronavirus outbreak of global health concern. Lancet. 2020;395(10223):470-473. doi:10.1016/S0140-6736(20)30185-92

2. Perlman S. Another decade, another coronavirus. New Engl J Med. 2020;382(8):760-762. doi:10.1056/NEJMe2001126

3. Gorbalenya AE, Baker SC, Baric RS, et al. The species severe acute respiratory syndrome-related coronavirus: classifying 2019-nCoV and naming it SARS-CoV-2. Nat Microbiol. 2020;5(4):536-544.4.

4. Wu JT, Leung K, Leung GM. Nowcasting and forecasting the potential domestic and international spread of the 2019-nCoV outbreak originating in Wuhan, China: a modelling study. Lancet. 2020;395:689. doi:10.1016/S0140-6736(20)30260-9

5. Gavriatopoulou M, Korompoki E, Fotiou D, et al. Organ-specific manifestations of COVID-19 infection. Clin Exp Med. 2020;7:1-14.

6. Glebov OO. Understanding SARS-CoV-2 endocytosis for COVID-19 drug repurposing. FEBS J. 2020;287:3664-3671. doi:10.1111/febs.15369

7. Ullah MA, Araf Y, Sarkar B, Moin AT, Reshad RA, Hasanur MD. Pathogenesis, diagnosis and possible therapeutic options for COVID19. J Clin Exp Invest. 2020;11:em00755. doi:10.29333/jcei/8564

8. Cardoso VMO, Moreira BJ, Comparetti EJ, et al. Is nanotechnology helping in the fight against COVID-19? Front Nanotechnol. 2020;2:588915. doi:10.3389/fnano.2020.588915

9. Rai M, Bonde S, Yadav A, et al. Nanotechnology-based promising strategies for the management of COVID-19: current development and constraints. Expert Rev Anti Infect Ther. 2020:1-10. doi:10.1080/ 14787210.2021 .1836961
10. WHO. COVID-19 dashboard. Available from: https://covid19. who.int/. Accessed June 15, 2021.

11. Lovato A, de Filippis C. Clinical presentation of COVID-19: a systematic review focusing on upper airway symptoms. Ear Nose Throat J. 2020;99(9):569-576.

12. Mizumoto K, Kagaya K, Zarebski A, Chowell G. Estimating the asymptomatic proportion of coronavirus disease 2019 (COVID19) cases on board the Diamond Princess cruise ship, Yokohama, Japan, 2020. Euro Surveill. 2020;25(10). doi:10.2807/1560-7917. ES.2020.25.10.2000180

13. Shereen MA, Khan S, Kazmi A, Bashir N, Siddique R. COVID19 infection: origin, transmission, and characteristics of human coronaviruses. $J$ Adv Res. 2020;24:91-98. doi:10.1016/j. jare.2020.03.005

14. Cai J, Sun W, Huang J, Gamber M, Wu J, He G. Indirect virus transmission in cluster of COVID-19 cases, Wenzhou, China, 2020. Emerg Infect Dis. 2020;26(6):1343-1345. doi:10.3201/ eid2606.200412

15. Chhantyal P. Cicada's antimicrobial nanotechnology solution for COVID free surfaces; 2020. Available from: https://www.azo nano.com/article.aspx?ArticleID=5621. Accessed June 12, 2021.

16. Kampf G, Todt D, Pfaender S, et al. Persistence of coronaviruses on inanimate surfaces and its inactivation with biocidal agents. $J$ Hosp Infect. 2020;104(3):246-251. doi:10.1016/j.jhin.2020.01.022

17. Tong Y, Ruiqi RM, Leung D, et al. Early transmission dynamics in Wuhan, China, of novel coronavirus-infected pneumonia. $N$ Engl $J$ Med. 2020;382(13):1199-1207. doi:10.1056/NEJMoa2001316

18. Sahu KK, Lal A, Mishra AK. Latest updates on COVID-2019: a changing paradigm shift. $J$ Med Virol. 2020;92(6):533-535. doi: $10.1002 / \mathrm{jmv} .25760$

19. Chaudhary V, Royal A, Chavali M, Yadav SK. Advancements in research and development to combat COVID-19 using nanotechnology. Nanotechnol Environ Eng. 2021;6(8). doi:10.1007/ s41204-021-00102-7

20. Yang Y. Impact of the COVID-19 pandemic on biomedical and clinical research. Matter. 2020;3:970-973. doi:10.1016/j. matt.2020.08.026

21. Taylor JR, Skeate JG, Kast WM. Annexin A2 in virus infection. Front Microbiol. 2018;9:2954. doi:10.3389/ fmicb.2018.02954

22. Vahedifard F, Chakravarthy K. Nanomedicine for COVID-19: the role of nanotechnology in the treatment and diagnosis of COVID-19. Emerg Mater. 2021;4:75-99. doi:10.1007/s42247021-00168-8

23. Marzo T, Messori L. A role for metal-based drugs in fighting COVID-19 infection? The case of auranofin. ACS Med Chem Lett. 2020;11:1067-1068. doi:10.1021/acsmedchemlett.0 c00190

24. Teralı K, Baddal B, Gülcan HO. Prioritizing potential ACE2 inhibitors in the COVID-19 pandemic: insights from a molecular mechanicsassisted structure-based virtual screening experiment. J Mol Graph Model. 2020;100:107697. doi:10.1016/j.jmgm.2020.107697

25. Seifi T, Kamali RA. Antiviral performance of graphene-based materials with emphasis on COVID-19: a review. Med Drug Discov. 2021;100099. doi:10.1016/j.medidd.2021.100099

26. Ahmad MZ, Ahmad J, Aslam M, Khan MA, Alasmary MY, Abdel-Wahab BA. Repurposed drug against COVID-19: nanomedicine as an approach for finding new hope in old medicines. Nano Express. 2021;2:022007. doi:10.1088/2632-959X/ abffed

27. Riva L, Yuan S, Yin X, et al. A large-scale drug repositioning survey for SARSCoV- 2 antivirals. bioRxiv. 2020. doi:10.1101/ 2020.04.16.044016

28. Senanayake SL. Drug repurposing strategies for COVID-19. Future Drug Discov. 2020;2(2). doi:10.4155/fdd-2020-0010 
29. Picaud F, Herlem G. Hydroxychloroquine and azithromycin molecular action against SARS-CoV-2 viral protein: a molecular dynamic Study. Austin J Nanomed Nanotechnol. 2021;9(1):1061.

30. Lagier J, Million M, Gautret P, et al. Outcomes of 3737 COVID-19 patients treated with hydroxychloroquine/azithromycin and other regimens in Marseille, France: a retrospective analysis. Travel Med Infect Dis. 2020;36:101791. doi:10.1016/j.tmaid.2020.101791

31. Duverger E, Herlem G, Picaud F. A potential solution to avoid overdose of mixed drugs in the event of Covid-19: nanomedicine at the heart of the Covid-19 pandemic. J Mol Graph Model. 2021;104:107834. doi:10.1016/j.jmgm.2021.107834

32. Bryant A, Lawrie TA, Dowswell T, et al. Ivermectin for prevention and treatment of COVID-19 infection: a systematic review, meta-analysis, and trial sequential analysis to inform clinical guidelines. Am. J. Ther. 2021;28(4):e434-e460. doi:10.1097/ MJT.0000000000001402

33. WHO. "Solidarity" clinical trial for COVID-19 treatments; 2020. Available from: https://www.who.int/emergencies/diseases/novel-cor onavirus-2019/global-research-on-novel-coronavirus-2019-ncov/soli darity-clinical-trial-for-covid-19-treatments. Accessed June 16, 2021.

34. Yang D. Application of nanotechnology in the COVID-19 pandemic. Int J Nanomedicine. 2021;16:623-649. doi:10.2147/IJN. S296383

35. Pinto D, Park YJ, Beltramello M, et al. Cross-neutralization of SARS-CoV-2 by a human monoclonal SARS-CoV antibody. Nature. 2020;583(7815):290-295. doi:10.1038/s41586-020-2349-y

36. Wang CY, Li WT, Drabek D, et al. A human monoclonal antibody blocking SARS-CoV-2 infection. Nat Commun. 2020;11:251. doi:10.1038/s41467-020-16256-y

37. Tanaka T, Narazaki M, Kishimoto T. Immunotherapeutic implications of IL-6 blockade for cytokine storm. Immunotherapy. 2016;8(8):959-970. doi:10.2217/imt-2016-0020121

38. Della-Torre E, Campochiaro C, Cavalli G, et al. Interleukin-6 blockade with sarilumab in severe COVID-19 pneumonia with systemic hyperinflammation: an open-label cohort study. Ann Rheum Dis. 2020;79(10):1277-1285. doi:10.1136/annrheumdis2020-218122123

39. Schrezenmeier E, Dorner T. Mechanisms of action of hydroxychloroquine and chloroquine: implications for rheumatology. Nat Rev Rheumatol. 2020;16(3):155-166. doi:10.1038/s41584-020-0372-x122

40. Zhou P, Yang XL, Wang XG, et al. A pneumonia outbreak associated with a new coronavirus of probable bat origin. Nature. 2020;579(7798):270. doi:10.1038/s41586-020-2012-7

41. Le TT, Andreadakis Z, Kumar A, et al. The COVID-19 vaccine development landscape. Nat Rev Drug Discov. 2020;19(5):305306. doi:10.1038/d41573-020-00151-8

42. Vazquez-Munoz R, Lopez-Ribot JL. Nanotechnology as an alternative to reduce the spread of COVID-19. Challenges. 2020;11 (2): 15 . doi: $10.3390 /$ challe11020015

43. Bentin J, Duverger E, Picaud F. Influence of nanotube section on carboplatin confinement. J Mol Model. 2019;25:72. doi:10.1007/ s00894-019-3965-z

44. Zakaria A, Picaud F, Guillaume YC, Gharbi T, Micheau O, Herlem G. Enhanced DR5 binding capacity of nanovectorized TRAIL compared to its cytotoxic version by affinity chromatography and molecular docking studies. J Mol Recognit. 2016;29 (9):406-414. doi:10.1002/jmr.2539

45. Alimardani V, Abolmaali SS, Tamaddon AM. Recent advances on nanotechnology-based strategies for prevention, diagnosis, and treatment of coronavirus infections. J Nanomater. 2021;Article ID 9495126, 20. doi:10.1155/2021/9495126

46. Melchor-Martínez EM, Torres Castillo NE, Macias-Garbett R, Lucero-Saucedo SL, Parra-Saldívar R, Sosa-Hernández JE. Modern world applications for nano-bio materials: tissue engineering and COVID-19. Front Bioeng Biotechnol. 2021;9:597958. doi:10.3389/fbioe.2021.597958
47. Sagadevan S, Periasamy M. A review on role of nanostructures in drug delivery system. Rev Adv Mater Sci. 2014;36:112-117.

48. Aberoumandi SM, Mohammadhosseini M, Abasi E, et al. An update on applications of nanostructured drug delivery systems in cancer therapy: a review. Artif Cells Nanomed Biotechnol. 2016;45(6):1058-1068. doi:10.1080/21691401.2016.1228658

49. Saravanan M, Mostafavi E, Vincent S, et al. Nanotechnologybased approaches for emerging and re-emerging viruses: special emphasis on COVID-19. Microb Pathog. 2021;156:104908. doi:10.1016/j.micpath.2021.104908

50. $\mathrm{Yu} \mathrm{Y,} \mathrm{Bu} \mathrm{F,} \mathrm{Zhou} \mathrm{H,} \mathrm{et} \mathrm{al.} \mathrm{Biosafety} \mathrm{materials:} \mathrm{an} \mathrm{emerging} \mathrm{new}$ research direction of materials science from the COVID-19 outbreak. Mater Chem Front. 2020;4:1930. doi:10.1039/D0QM00255K

51. Chauhan PS, Yadav D, Dubey A, Jin JO. Nano-biomaterials as sensing and therapeutic tool to mitigate viral pathogenesis with special reference to COVID-19. Curr Pharm Des. 2021;27. doi:10.2174/1381612827666210203142934

52. Hassanzadeh P. Nanotheranostics against COVID-19: from multivalent to immune-targeted materials. Control Release. 2020;328:112-126. doi:10.1016/j.jconrel.2020.08.060

53. Chan WCW. Nano research for COVID-19. ACS Nano. 2020;14 (4):3719-3720. doi:10.1021/acsnano.0c02540

54. Wong XY, Sena-Torralba A, Álvarez-diduk R, Muthoosamy K, Merkoçi A. Nanomaterials for nanotheranostics: tuning their properties according to disease needs. ACS Nano. 2020;14:2585-2627. doi:10.1021/acsnano.9b08133

55. Lukassen S, Chua RL, Trefzer T, et al. SARS-CoV-2 receptor ACE2 and TMPRSS2 are primarily expressed in bronchial transient secretory cells. EMBO J. 2020;39:e105114. doi:10.15252/ embj.2020105114

56. Saghazadeh A, Rezaei N. Biosensing surfaces and therapeutic biomaterials for the central nervous system in COVID-19. Emerg Mater. 2021;4:293-312. doi:10.1007/s42247-02100192-8

57. Costantino HR, Illum L, Brandt G, Johnson PH, Quay SC. Intranasal delivery: physicochemical and therapeutic aspects. Int $J \quad$ Pharm. 2007;337(1-2):1-24. doi:10.1016/j.ijpharm.20 07.03 .025

58. Kim M, Park J, Shon Y, et al. Nanotechnology and vaccine development: a review. Asian J Pharm Sci. 2014;9(5):227-235. doi:10.1016/j.ajps.2014.06.002

59. Cao LZ, Wang ZS, Wang B. Application of nano biomaterials in antiviral vaccine adjuvant. Chin J Appl Chem. 2021;38(5):572.

60. Mamo T, Poland GA. Nanovaccinology: the next generation of vaccines meets 21 st century materials science and engineering. Vaccine. 2012;30:6609-6611. doi:10.1016/j.vaccine.2012.08.023

61. Weiss C, Carriere M, Fusco L, et al. Toward nanotechnologyenabled approaches against the COVID-19 pandemic. ACS Nano. 2020;14:6383-6406. doi:10.1021/acsnano.0c03697

62. Huang H, Fan C, Li M, et al. COVID-19: a call for physical scientists and engineers. ACS Nano. 2020;14(4):3747-3754. doi:10.1021/acsnano.0c02618

63. Cook TM. Personal protective equipment during the coronavirus disease (COVID) 2019 pandemic - a narrative review. Anaesthesia. 2020;75(7):920-927. doi:10.1111/anae.15071

64. Garai A, Gorai T. Improvement of personal protection for Covid19 infection. Int Res J Mod. 2020;02(06).

65. Thind PS, Sareen A, Singh DD, Singh S, John S. Compromising situation of India's bio-medical waste incineration units during pandemic outbreak of COVID-19: associated environmentalhealth impacts and mitigation measures. Environ Pollut. 2021;276:116621. doi:10.1016/j.envpol.2021.116621

66. Wang Z, An C, Chen X, Lee K, Zhang B, Feng Q. Disposable masks release microplastics to the aqueous environment with exacerbation by natural weathering. $J$ Hazard Mater. 2021;417:126036. doi:10.1016/j.jhazmat.2021.126036 
67. Akhbarizadeh R, Dobaradaran S, Nabipour I, et al. Abandoned Covid-19 personal protective equipment along the Bushehr shores, the Persian Gulf: an emerging source of secondary microplastics in coastlines. Mar Pollut Bull. 2021;168:112386. doi:10.1016/j.marpolbul.2021.112386

68. De-la-torre GE, Rakib RJ, Pizarro-Ortega CI, Dioses-Salinas DC. Occurrence of personal protective equipment (PPE) associated with the COVID-19 pandemic along the coast of Lima, Peru. Sci Total Environ. 2021;774:145774. doi:10.1016/j. scitotenv.2021.145774

69. Rakib RJ, De-la-torre GE, Pizarro-Ortega CI, Dioses-Salinas DC, Al-Nahian S. Personal protective equipment (PPE) pollution driven by the COVID-19 pandemic in Cox's Bazar, the longest natural beach in the world. Mar Pollut Bull. 2021;169:112497. doi:10.1016/j.marpolbul.2021.112497

70. Hasan NA, Heal RD, Bashar A, Haque MM. Face masks: protecting the wearer but neglecting the aquatic environment? - A perspective from Bangladesh. Environ Challenges. 2021;4:100126. doi:10.1016/j.envc.2021.100126

71. Rodríguez NB, Formentini G, Favi C, Marconi M. Environmental implication of personal protective equipments, in the pandemic era: LCA comparison of face masks typologies. Procedia CIRP. 2021;98:306-311. doi:10.1016/j.procir.2021.01.108

72. Ju JTJ, Boisvert LN, Zuo YY. Face masks against COVID-19: standards, efficacy, testing and decontamination methods. Adv Colloid Interface Sci. 2021;292:102435. doi:10.1016/j.cis.2021.102435

73. Mainardes RM, Diedrich C. The potential role of nanomedicine on COVID-19 therapeutics. Ther Deliv. 2020;11(7):411-414. doi:10.4155/tde-2020-0069

74. Bhavana V, Thakor P, Singh SB, Mehra NK. COVID-19. Pathophysiology, treatment options, nanotechnology approaches, and research agenda to combating the SARS-CoV2 pandemic. Life Sci. 2020;261:118336. doi:10.1016/j.lfs.2020.118336

75. Allawadhi P, Singh V, Khurana A, et al. Silver nanoparticle based multifunctional approach for combating COVID-19. Sens Int. 2021;2:100101. doi:10.1016/j.sint1.2021.100101

76. Rai M, Bonde S, Yadav A, et al. Nanotechnology as a shield against COVID-19: current advancement and limitations. Viruses. 2021;13:1224. doi:10.3390/v13071224

77. Gregory AE, Titball R, Williamson D. Vaccine delivery using nanoparticles. Front Cell Infect Microbiol. 2013;3:152.

78. Lauster D, Klenk S, Ludwig K, et al. Phage capsid nanoparticles with defined ligand arrangement block influenza virus entry. Nat Nanotechnol. 2020;15(5):373-379. doi:10.1038/s41565-020-0660-2

79. Adhikari S, Adhikari U, Mishra A, Guragain BS. Nanomaterials for diagnostic, treatment and prevention of COVID-19. Appl Sci Technol Ann. 2020;1(1):155-164. doi:10.3126/asta.v1i1.30295

80. Jindal S, Gopinath P. Nanotechnology based approaches for combatting COVID-19 viral infection. Nano Express. 2020;1:022003. doi:10.1088/2632-959X/abb714

81. Singh A, Kumar M, Dubey AK. Effect of pre-existing diseases on COVID-19 infection and role of new sensors and biomaterials for its detection and treatment. Med Devices Sens. 2021;4:e10140. doi:10.1002/mds3.10140

82. Varahachalam SP, Lahooti B, Chamaneh M, et al. Nanomedicine for the SARS-CoV-2: state-of-the-art and future prospects. Int $J$ Nanomedicine. 2021;16:539-560. doi:10.2147/IJN.S283686

83. Tyagi PK, Tyagi S, Kumar A, Ahuja A, Gola D. Contribution of nanotechnology in the fight against COVID-19. Biointerface Res Appl Chem. 2021;11(1):8233-8241. doi:10.33263/ BRIAC111.82338241

84. Moitra P, Alafeef M, Dighe K, Frieman MB, Pan D. Selective naked-eye detection of SARS-CoV-2 mediated by $\mathrm{N}$ gene targeted antisense oligonucleotide capped plasmonic nanoparticles. ACS Nano. 2020;14(6):7617-7627. doi:10.1021/acsnano.0c0 3822277
85. Vashist SK. In vitro diagnostic assays for COVID-19: recent advances and emerging trends. Diagnostics. 2020;10(4):202. doi:10.3390/diagnostics 10040202

86. Candanosa MR. Here's how nanoparticles could help us get closer to a treatment for COVID-19; 2020. Available from: https://news.northeastern.edu/2020/03/04/heres-how-nanoparti cles-could-help-us-get-closer-to-a-treatment-for-covid-19/.

Accessed June 10, 2021.

87. Chen X, Miller A, Cao S, et al. Rapid escherichia coli trapping and retrieval from bodily fluids via a three-dimensional beadstacked nanodevice. ACS Appl Mater Interfaces. 2020;12 (7):7888-7896. doi:10.1021/acsami.9b19311

88. Qiu G, Gai Z, Tao Y, Schmitt J, Kullak-Ublick GA, Wang J. Dual-functional plasmonic photothermal biosensors for highly accurate severe acute respiratory syndrome coronavirus 2 detection. ACS Nano. 2020;14:5268. doi:10.1021/acsnano.0c02439

89. Chen YT, Kolhatkar AG, Zenasni O, Xu S, Lee TR. Biosensing using magnetic particle detection techniques. Sensors. 2017;17:2300. doi:10.3390/s17102300

90. Medhi R, Srinoi P, Ngo N, Tran H, Lee TR. Nanoparticle-based strategies to combat COVID-19. ACS Appl Nano Mater. 2020;3:8557-8580. doi:10.1021/acsanm.0c01978

91. Rodgers P. Nanoscience and Technology. Nature Publishing Group; 2020:368. doi:10.1142/7439

92. Seo G, Lee G, Kim MJ, et al. Rapid detection of COVID-19 causative virus (SARS-CoV-2) in human nasopharyngeal swab specimens using field-effect transistor-based biosensor. ACS Nano. 2020;14(9):12257-12258. doi:10.1021/acsnano.0c06 726276

93. Alphandéry E. The potential of various nanotechnologies for coronavirus diagnosis/treatment highlighted through a literature analysis. Bioconjug Chem. 2020;31:1873-1882. doi:10.1021/acs. bioconjchem.0c00287

94. Baker AN, Richards SJ, Guy CS, et al. The SARS-COV-2 spike protein binds sialic acids and enables rapid detection in a lateral flow point of care diagnostic device. ACS Cent Sci. 2020;6 (11):2046-2052. doi:10.1021/acscentsci.0c00855

95. Paliwal P, Sargolzaei S, Bhardwaj SK, Bhardwaj V, Dixit C, Kaushik A. Grand challenges in bio-nanotechnology to manage COVID-19 pandemic. Front Nanotechnol. 2020;2:5. doi:10.3389/ fnano.2020.571284

96. Gupta R, Sagar P, Priyadarshi N, et al. Nanotechnology-based approaches for the detection of SARS-CoV-2. Front Nanotechnol. 2020;2:589832. doi:10.3389/fnano.2020.589832

97. Udugama B, Kadhiresan P, Kozlowski HN, et al. Diagnosing COVID-19: the disease and tools for detection. ACS Nano. 2020;14(4):3822-3835. doi:10.1021/acsnano.0c02624

98. Chandra P. Miniaturized label-free smartphone assisted electrochemical sensing approach for personalized COVID-19 diagnosis. Sens Int. 2020;1:100019. doi:10.1016/j.sintl.2020.100019

99. Nanotechnology Database. COVID-19 rapid test cassette. Available from: https://product.statnano.com/product/11669/ covid-19-rapid-test-cassette. Accessed June 19, 2021.

100. InBios International, Inc. FDA emergency use authorized. Smart detect SARS-CoV-2 RRT-PCR Kit/48T. [online]; October, 2020. Available from: https://inbios.com/smart-detecttm-sars-cov-2-rrtpcr-kit/. Accessed June 19, 2021.

101. Ahmed SR, Kang SW, Oh S, Lee J, Neethirajan S. Chiral zirconium quantum dots: a new class of nanocrystals for optical detection of coronavirus. Heliyon. 2018;4:e00766. doi:10.1016/j. heliyon.2018.e00766

102. Broughton JS, Deng X, Yu G, et al. Rapid detection of 2019 Novel Coronavirus SARS-CoV-2 using a CRISPR-based DETECTR lateral flow assay. medRxiv. 2020. doi:10.1101/ 2020.03.06.20032334 
103. Chen Z, Zhang Z, Zhai X, et al. Rapid and sensitive detection of anti-SARS-CoV-2 IgG, using lanthanide-doped nanoparticlesbased lateral flow immunoassay. Anal Chem. 2020;92:7226-7231.

104. Chacón-Torres CJ, Reinoso C, Navas-León DG, Briceño S, González G. Optimized and scalable synthesis of magnetic nanoparticles for RNA extraction in response to developing countries' needs in the detection and control of SARS-CoV-2. Sci Rep Nat Res. 2020;10:19004. doi:10.1038/s41598-020-75798-9

105. Itani R, Tobaiqy M, Al Faraj A. Optimizing use of theranostic nanoparticles as a life-saving strategy for treating COVID-19 patients. Theranostics. 2020;10(13):5932-5942. doi:10.7150/ thno.46691

106. Sharmiladevi P, Girigoswami K, Haribabu V, Girigoswami A. Nano-enabled theranostics for cancer. Mater Adv. 2021;2:2876. doi:10.1039/d1ma00069a

107. Siafaka PI, Okur NU, Karantas ID, Okur ME, Gündogdu EA. Current update on nanoplatforms as therapeutic and diagnostic tools: a review for the materials used as nanotheranostics and imaging modalities. Asian $J$ Pharm Sci. 2021;16:24-46. doi:10.1016/j.ajps.2020.03.003

108. Miyazawa T, Itaya M, Burdeos GC, Nakagawa K, Miyazawa T. A critical review of the use of surfactant-coated nanoparticles in nanomedicine and food nanotechnology. Int $J$ Nanomedicine. 2021;16:3937-3999.

109. Hu TY, Frieman M, Wolfram J. Insights from nanomedicine into chloroquine efficacy against COVID-19. Nat Nanotechnol. 2020;15(4):247-249. doi:10.1038/s41565-020-0674-9

110. Lammers T, Sofias AM, van der Meel R, et al. Dexamethasone nanomedicines for COVID-19. Nat Nanotechnol. 2020;15 (8):622-624. doi:10.1038/s41565-020-0752-Z

111. Lu H, Wang J, Wang T, Zhong J, Bao Y, Hao H. Recent progress on nanostructures for drug delivery applications. J Nanomater. 2016:Article ID 5762431, 12. doi:10.1155/2016/5762431

112. Ribeiro LNM, Fonseca BB. The role of pharmaceutical nanotechnology in the time of COVID-19 pandemic. Future Microbiol. 2020;15(16):1571-1582. doi:10.2217/fmb-2020-0118

113. Molinaro R, Pasto A, Taraballi F, et al. Biomimetic nanoparticles potentiate the anti-inflammatory properties of dexamethasone and reduce the cytokine storm syndrome: an additionalWeapon against COVID-19? Nanomaterials. 2020;10:2301. doi:10.3390/ nano10112301

114. Tai T, Wu T, Wu H, et al. A strategy to treat COVID-19 disease with targeted delivery of inhalable liposomal hydroxychloroquine: a Non-clinical Pharmacokinetic Study. Clin Transl Sci. 2021;14(1):132-136. doi:10.1111/cts.12923

115. Morad R, Akbari M, Rezaee P, Koochaki A, Maaza M, Jamshidi Z. First principle simulation of coated hydroxychloroquine on $\mathrm{Ag}$, Au and Pt nanoparticles. Sci Rep Nat. 2021;11:2131. doi:10.1038/ s41598-021-81617-6

116. US. National Library of Medicine, ClinicalTrials.gov. Efficacy and safety of liposomal lactoferrin in COVID-19 patients with mild-to-moderate disease and in COVID-19 asymptomatic patients; May 14, 2021. Available from: https://clinicaltrials.gov/ ct2/show/NCT04475120. Accessed June 18, 2021.

117. Zhang Q, Honko A, Zhou J, et al. Cellular nanosponges inhibit SARS-CoV-2 infectivity. Nano Lett. 2020;20(7):5570-5574. doi:10.1021/acs.nanolett.0c02278244

118. Mehranfar A, Izadyar M. Theoretical design of functionalized gold nanoparticles as antiviral agents against severe acute respiratory syndrome coronavirus 2 (SARS-CoV-2). J Phys Chem Lett. 2020;11:10284-10289. doi:10.1021/acs.jpclett.0c02677

119. ChemistryViews.org. Membrane-based ACE2-rich nanoparticles against COVID-19. Available from: https://www.chemistryviews. org/details/news/11293970/Membrane-Based_ACE2-Rich Nanoparticles_against_COVID-19.html. Accessed June 18, 2021.
120. Vartak R, Patil SM, Saraswat A, Patki M, Kunda NK, Patel K. Aerosolized nanoliposomal carrier of remdesivir: an effective alternative for COVID-19 treatment in vitro. Nanomedicine. 2021;16(14):113. doi:10.2217/nnm-2020-0475

121. Nair SC, Joseph SK, Arya MA, Thomas S. State-of-the-art nanotechnology based drug delivery strategies to combat Covid-19. Int J App Pharm. 2021;13(3):18-29. doi:10.22159/ijap.2021v1 3i3.40865

122. Wiersinga WJ, Rhodes A, Cheng AC, Peacock SJ, Prescott HC. Pathophysiology, transmission, diagnosis, and treatment of coronavirus disease 2019 (COVID-19): a review. JAMA. 2020;324 (8):782-793. doi:10.1001/jama.2020.12839

123. Dwivedi R. The role of nanotechnology in the fight against COVID-19; March 15, 2021. Available from: https://www.newsmedical.net/news/20210315/The-role-of-nanotechnology-in-thefight-against-COVID-19.aspx. Accessed June 13, 2021.

124. Jarai BM, Stillman Z, Attia L, Decker GE, Bloch ED, Fromen CA. Evaluating UiO-66 metal-organic framework nanoparticles as acid-sensitive carriers for pulmonary drug delivery applications. ACS Appl Mater Interfaces. 2020;12:38989. doi:10.1021/ acsami.0c10900

125. Ruiz-Hitzky E, Darder M, Wicklein B, Martín-Sampedro R, Aranda P. Nanotechnology responses to COVID-19. Adv Healthcare Mater. 2020;9:2000979. doi:10.1002/adhm.202000979

126. Ghosh AR, Bhooshitha AN, Chandan HM, Krishna KL. Possible insights into the use of silver nanoparticles in targeting SARSCoV-2 (COVID-19). Indian J Pharm Educ Res. 2021;55(2):319329. doi:10.5530/ijper.55.2.69

127. Kheirollahpour M, Mehrabi M, Dounighi N, et al. Nanoparticles and vaccine development. Pharm Nanotech. 2020;8:6-21. doi:10.2174/2211738507666191024162042

128. Smith DM, Simon JK, Baker JR. Applications of nanotechnology for immunology. Nat Rev Immunol. 2013;13:592-605. doi: $10.1038 /$ nri3488

129. Campos EVR, Pereira AES, de Oliveira JJ, et al. How can nanotechnology help to combat COVID-19? Opportunities and urgent need. J Nanobiotechnol. 2020;18:125. doi:10.1186/ s12951-020-00685-4

130. Palestino G, García-Silva I, González-Ortega O, RosalesMendoza S. Can nanotechnology help in the fight against COVID-19? Expert Rev Anti Infect Ther. 2020;18:849-864. doi:10.1080/14787210.2020.1776115

131. Colombani T, Rogers ZJ, Eggermont LJ, Bencherif SA. Harnessing biomaterials for therapeutic strategies against COVID-19. Emerg Mater. 2021;4:9-18. doi:10.1007/s42247021-00171-z

132. Seyfoori A, Amereh M, Dabiri SMH, Askari E, Walsh T, Akbari M. The role of biomaterials and three dimensional (3D) in vitro tissue models in fighting against COVID-19. Biomater Sci. 2021;9:1217. doi:10.1039/D0BM01616K

133. Patil-Sen Y, Bose K. Advances in nano-biomaterials and their applications in biomedicine. Emerg Top Life Sci. 2021;5(1):169176. doi:10.1042/ETLS20200333

134. Chakhalian D, Shultz RB, Miles CE, Kohn J. Opportunities for biomaterials to address the challenges of COVID-19. J Biomed Mater Res. 2020;108:1974-1990. doi:10.1002/jbm.a.37059

135. Ertas YN, Mahmoodi M, Shahabipour F, et al. Role of biomaterials in the diagnosis, prevention, treatment, and study of corona virus disease 2019 (COVID-19). Emerg Mater. 2021;4:35-55. doi:10.1007/s42247-021-00165-X

136. Ghaffari M, Mollazadeh-Bajestani M, Moztarzadeh F, Uludağ H, Hardy JG, Mozafari M. An overview of the use of biomaterials, nanotechnology, and stem cells for detection and treatment of COVID-19: towards a framework to address future global pandemics. Emerg Mater. 2021;4:19-34. doi:10.1007/s42247-02000143-9 
137. Liu Z. Featuring advanced translational strategies: principles, techniques, devices and applications. Cancer Lett. 2020. doi:10.1016/j.canlet.2020.06.003

138. Jarai BM, Stillman Z, Bomb K, Kloxin AM, Fromen CA. Biomaterials-based opportunities to engineer the pulmonary host immune response in COVID-19. ACS Biomater Sci Eng. 2021;7 (5):1742-1764. doi:10.1021/acsbiomaterials.0c01287

139. Cao X. COVID-19: immunopathology and its implications for therapy. Nat Rev Immunol. 2020;20(5):269-270. doi:10.1038/ s41577-020-0308-3

140. Chintagunta AD, Krishna SM, Nalluru S, Kumar SNS. Nanotechnology: an emerging approach to combat COVID-19. Emerg Mater. 2021;4:119-130. doi:10.1007/s42247-021-00178-6

141. Rao L, Xia S, Xu W, et al. Decoy nanoparticles protect against COVID-19 by concurrently adsorbing viruses and inflammatory cytokines. Proc Natl Acad Sci USA. 2020;117(44):27141-27147. doi:10.1073/pnas.2014352117243

142. Owens R. Protein production UK; 2020. Available from: https://www. rfi.ac.uk/projects/protein-production-uk/. Accessed June 15, 2021.

143. Collins F. Restoring the elastic of life. Available from: https:// www.elastrin-therapeutics.com/. Accessed June 12, 2021.

144. Alshabanah LA, Hagar M, Al-Mutabagani LA, et al. Hybrid nanofibrous membranes as a promising functional layer for personal protection equipment: manufacturing and antiviral/antibacterial assessments. Polymers. 2021;13:1776. doi:10.3390/ polym 13111776

145. Carvalho APA, Conte-Junior CA. Recent advances on nanomaterials to COVID-19 management: a systematic review on antiviral/virucidal agents and mechanisms of SARS-CoV-2 inhibition/inactivation. Glob Chall. 2021;5:2000115. doi:10.1002/gch2.202000115

146. Ansari SH, Islam F, Sameem M. Influence of nanotechnology on herbal drugs: a Review. J. Adv. Pharm. Technol. Res. 2012;3 (3):142. doi:10.4103/2231-4040.101006

147. Sandhiya V, Ubaidulla U. A review on herbal drug loaded into pharmaceutical carrier techniques and its evaluation process. Future J Pharm Sci. 2020;6:51. doi:10.1186/s43094-020-00050-0

148. Benarba B, Pandiella A. Medicinal plants as sources of active molecules against COVID-19. Front Pharmacol. 2020;11:1189. doi:10.3389/fphar.2020.01189

149. Huang J, Tao G, Liu J, Cai J, Huang Z, Chen J-X. Current prevention of COVID-19: natural products and herbal medicine. Front Pharmacol. 2020;11:588508. doi:10.3389/fphar.2020.588508

150. Khadka D, Dhamala MK, Li F, et al. The use of medicinal plants to prevent COVID-19 in Nepal. J Ethnobiol Ethnomed. 2021;17:26. doi:10.1186/s13002-021-00449-w

151. Kurniawan DW, Ikhsanudin A. Potential of Jamu in nanotechnology perspective as an alternative treatment for Covid-19. Pharm Sci Res. 2020;7(3):123-131. doi:10.7454/psr.v7i3.1082

152. Zhao Z, Xiao Y, Xu L, et al. Glycyrrhizic acid nanoparticles as antiviral and anti-inflammatory agents for COVID-19 treatment. ACS Appl Mater Interfaces. 2021;13:20995-21006. doi:10.1021/ acsami.1c02755

153. Adeleye OA, Femi-Oyewo MN, Bamiro OA, et al. Ethnomedicinal herbs in African traditional medicine with potential activity for the prevention, treatment, and management of coronavirus disease 2019. Future J Pharm Sci. 2021;7(72). doi:10.1186/s43094-021-00223-5

154. Karuppath S, Pillai P, Nair SV, Lakshmanan V. Comparison and existence of nanotechnology in traditional alternative medicine: an onset to future medicine. Nanosci Nanotechnol. 2018;8:13-25. doi:10.2174/2210681206666160402004710

155. Alfaisal University, department of microbiology and immunology. Nature's answer to Covid-19 treatment; 2021. Available from: https://www.timeshighereducation.com/hub/p/natures-answercovid-19-treatment. Accessed June 16, 2021.
156. D'Arrigo JS. Nanotargeting of drug(s) for delaying Dementia: relevance of Covid-19 impact on Dementia. Am J Alzheimers Dis Other Demen. 2020;35:1-12. doi:10.1177/1533317520976761

157. Ritchie K, Chan D, Watermeyer T. The cognitive consequences of the COVID-19 epidemic: collateral damage? Brain Commun. 2020;2(2):fcaa069. doi:10.1093/braincomms/fcaa069

158. Alamolhoda SZ, Zarghami N, Kahroba H, et al. Isothermal amplification of nucleic acids coupled with nanotechnology and microfluidic platforms for detecting antimicrobial drug resistance and beyond. Adv Pharm Bull. 2021. doi:10.34172/apb.2022.004

159. Kusumoputro S, Tseng S, Tse J, et al. Potential nanoparticle applications for prevention, diagnosis, and treatment of COVID19. View. 2020;1:20200105. doi:10.1002/VIW.20200105

160. Tang Z, Zhang X, Shu Y, Guo M, Zhang H, Tao W. Insights from nanotechnology in COVID-19 treatment. Nano Today. 2021;36:101019. doi:10.1016/j.nantod.2020.101019

161. Hobson J, Savage A, Dwyer A, et al. Scalable nanoprecipitation of niclosamide and in vivo demonstration of long-acting delivery after intramuscular injection. Nanoscale. 2021;13:6410-6416. doi:10.1039/D1NR00309G

162. Vivekanandhan K, Shanmugam P, Barabadi H, et al. Emerging therapeutic approaches to combat COVID-19: present status and future perspectives. Front Mol Biosci. 2021;8:604447. doi:10.3389/fmolb.2021.604447

163. Nikaeen G, Abbaszadeh S, Yousefinejad S. Application of nanomaterials in treatment, anti-infection and detection of coronaviruses. Future Med. 2020;15:1743-5889.

164. Tai WB, He L, Zhang XJ, et al. Characterization of the receptorbinding domain (RBD) of 2019 novel coronavirus: implication for development of RBD protein as a viral attachment inhibitor and vaccine. Cell Mol Immunol. 2020;17(6):613-620. doi:10.1038/s41423-020-0400-4

165. Reddy ST, van der Vlies AJ, Simeoni E, et al. Exploiting lymphatic transport and complement activation in nanoparticle vaccines. Nat Biotechnol. 2007;25(10):1159-1164. doi:10.1038/ nbt1332293

166. Bachmann MF, Jennings GT. Vaccine delivery: a matter of size, geometry, kinetics and molecular patterns. Nat Rev Immunol. 2010;10(11):787-796. doi:10.1038/nri2868

167. Zeng C, Hou X, Yan J, et al. Leveraging mRNAs sequences to express SARS-CoV-2 antigens in vivo. bioRxiv. 2020. doi:10.1101/2020.04.01.019877

168. Kuate S, Cinatl J, Doerr HW, Uberla K. Exosomal vaccines containing the $\mathrm{S}$ protein of the SARS coronavirus induce high levels of neutralizing antibodies. Virology. 2007;362(1):26-37. doi:10.1016/j.virol.2006.12.011

169. Abdellatif AAH, Tawfeek HM, Abdelfattah A, Batiha GE, Hetta HF. Recent updates in COVID-19 with emphasis on inhalation therapeutics: nanostructured and targeting systems. J Drug Deliv Sci Technol. 2021;63:102435. doi:10.1016/j.jddst.2021.102435

170. Cocozza F, Piovesana E, Névo N, et al. Extracellular vesicles containing ACE2 efficiently prevent infection by SARS-CoV-2 spike protein-containing virus. J Extracell Vesicles. 2020;10(2): e12050. doi:10.1002/jev2.12050

171. Kim J, Mukherjee A, Nelson D, Jozic A, Sahay G. Rapid generation of circulating and mucosal decoy ACE2 using mRNA nanotherapeutics for the potential treatment of SARS-CoV-2. bioRxiv. 2020. doi:10.1101/2020.07.24.205583

172. Ting D, Dong N, Fang L, et al. Multisite inhibitors for enteric coronavirus: antiviral cationic carbon dots based on curcumin. ACS Appl Nano Mater. 2018;1:5451-5459. doi:10.1021/acsanm.8b00779

173. Ansari MA, Almatroudi A, Alzohairy MA, et al. Lipid-based nano delivery of Tat-peptide conjugated drug or vaccine-promising therapeutic strategy for SARS-CoV-2 treatment. Expert Opin Drug Deliv. 2020;17(12):1671-1674. doi:10.1080/ 17425247.2020 .1813712 
174. Thi TTH, Suys EJA, Lee JS, Nguyen DH, Park KD, Truong NP. Lipid-based nanoparticles in the clinic and clinical trials: from cancer nanomedicine to COVID-19 vaccines. Vaccines. 2021;9:359. doi:10.3390/vaccines9040359

175. Greinacher A, Thiele T, Warkentin TC, et al. Thrombocytopenic disorder resembling heparin-induced thrombocytopenia following coronavirus-19 vaccination. Res Sq. 2021. doi:10.21203/rs.3.rs362354/v1

176. Singh P, Singh D, Sa P, Mohapatra P, Khuntia A, Sahoo SK. Insights from nanotechnology in COVID-19: prevention, detection, therapy and immunomodulation. Nanomedicine. 2021;16 (14):1219-1235. doi:10.2217/nnm-2021-0004

177. WHO. COVID-19 vaccine tracker and landscape; June 18, 2021. Available from: https://www.who.int/publications/m/item/draft-land scape-of-covid-19-candidate-vaccines. Accessed June 20, 2021.

178. Facciolà $\mathrm{A}$, Visalli $\mathrm{G}$, Laganà $\mathrm{P}$, et al. The new era of vaccines: the "nanovaccinology". Eur Rev Med Pharmacol Sci. 2019;23:7163-7182.

179. de Vrieze J. Suspicions grow that nanoparticles in Pfizer's COVID-19 vaccine trigger rare allergic reactions. Daily news on Science AAAS; December 21, 2020. Available from: https:// www.sciencemag.org/news/2020/12/suspicions-grow-nanoparti cles-pfizer-s-covid-19-vaccine-trigger-rare-allergic-reactions. Accessed July 20, 2021.

180. Dwivedi R. Research looks at inflammatory nature of lipid nanoparticle component in mRNA vaccines. Posted in: Medical Research News | Disease/Infection News; March 15, 2021. Available from: https://www.news-medical.net/news/20210315/ Research-looks-at-inflammatory-nature-of-lipid-nanoparticle-com ponent-in-mRNA-vaccines.aspx. Accessed July 20, 2021.

181. Technov R. Understanding the nanotechnology in COVID-19 vaccines. Written for CAS, American Chemical Society; February 18 Available from: https://www.cas.org/resource/blog/understandingnanotechnology-covid-19-vaccines. Accessed July 20, 2021.

182. Mortimer GM, Minchin RF. Nanotoxicology and nanovaccines. Elsevier Inc; 2017. Available from: https://espace.library.uq.edu. au/view/UQ:439461. Accessed July 20, 2021.

183. Zhao L, Setha A, Wibowoa N, et al. Nanoparticle vaccines. Vaccine. 2014;32:327-337. doi:10.1016/j.vaccine.2013.11.069

184. Balagna C, Perero S, Percivalle E, et al. Virucidal effect against coronavirus SARS-CoV-2 of a silver nanocluster/silica composite sputtered coating. Open Ceram. 2020;1:100006. doi:10.1016/j. oceram.2020.100006

185. Ramaiah GB, Tegegne A, Melese B. Developments in nanomaterials and analysing its role in fighting COVID-19. Mater Today. 2021.

186. El-Megharbel SM, Alsawat M, Al-Salmi FA, Hamza RZ. Utilizing of (zinc oxide nano-spray) for disinfection against "SARS-CoV-2" and testing its biological effectiveness on some biochemical parameters during (COVID-19 pandemic) - " $\mathrm{ZnO}$ nanoparticles have antiviral activity against (SARS-CoV-2)". Coatings. 2021;11(4):388. doi:10.3390/coatings11040388

187. Valdez-Salas B, Beltran-Partida E, Nelson Cheng JSC, ValdezSalas EA, Curiel-Alvarez M, Ibarra-Wiley R. Promotion of surgical masks antimicrobial activity by disinfection and impregnation with disinfectant silver nanoparticles. Int J Nanomedicine. 2021;16:2689. doi:10.2147/IJN.S301212

188. Thakur A, Sathyamurthy R, Ramalingam V, et al. A case study of SARS-CoV-2 transmission behavior in severe air-polluted city (Delhi, India) and potential usage of graphene based materials for filtering the air-pollutants and controlling/monitoring the COVID-19 pandemic. Environ Sci Process Impacts. 2021.

189. Wu J, Zhou H, Zhou J, et al. Meltblown fabric vs nanofiber membrane, which is better for fabricating personal protective equipments. Chin J Chem Eng. 2020. doi:10.1016/j.cjche.2020.10.022
190. Al-Sayah MH. Chemical disinfectants of COVID-19: an overview. $J$ Water Health. 2020;18(5):843-848. doi:10.2166/wh.2020.108

191. Laister D. Hull firm's nanotech solution aims to stop COVID-19 spread in its tracks. Available from: https://www.businesslive.co. uk/enterprise/hullfirmsnanotechsolutionaims19352722. Accessed June 17, 2021.

192. Mouritz AP, Galos J, Linklater DP, et al. Towards antiviral polymer composites to combat COVID-19 transmission. Nano Select. 2021:1-11. doi:10.1002/nano.202100078

193. Nakamura S, Sato M, Sato Y, et al. Synthesis and application of silver nanoparticles (Ag NPs) for the prevention of infection in healthcare workers. Int J Mol Sci. 2019;20:3620. doi:10.3390/ ijms 20153620

194. Sportelli MC, Izzi M, Kukushkina EA, et al. Can nanotechnology and materials science help the fight against SARS-CoV-2? Nanomaterials. 2020;10(4):802. doi:10.3390/nano10040802

195. Abed EM, Hoseini-Alfatemi SM, Sabati H, Gaskarei MAK, Delpasand K, Ghasemi M. Use of nanotechnology in the diagnosis and treatment of coronavirus. J Curr Biomed Rep. 2021;2 (2):ISSN:2717-1906.

196. Erkoc P, Ulucan-Karnak F. Nanotechnology-based antimicrobial and antiviral surface coating strategies. Prosthesis. 2021;3:25-52. doi:10.3390/prosthesis3010005

197. Jeremiah SS, Miyakawa K, Morita T, Yamaoka Y. Potent antiviral effect of silver nanoparticles on SARS-CoV-2. Biochem Biophys Res Commun. 2020;533:195-200. doi:10.1016/j.bbrc.2020.09.018

198. Joe YH, Park DH, Hwang J. Evaluation of Ag nanoparticle coated air filter against aerosolized virus: anti-viral efficiency with dust loading. J Hazard Mater. 2016;301:547-553. doi:10.1016/j. jhazmat.2015.09.017

199. Warnes SL, Little ZR, Keevil CW. Human coronavirus 229E remains infectious on common touch surface materials. Mbio. 2015;6(6). doi:10.1128/mBio.01697-15

200. van Doremalen N, Bushmaker T, Morris DH, et al. Aerosol and surface stability of SARS-CoV-2 as compared with SARS-CoV-1. New Engl J Med. 2020;382(16):1564-1567. doi:10.1056/ NEJMc2004973

201. Borkow G, Zhou SS, Page T, Gabbay J. A novel anti-influenza copper oxide containing respiratory face mask. PLoS One. 2010;5 (6):e11295. doi:10.1371/journal.pone.0011295

202. Sportelli MC, Longano D, Bonerba E, et al. Electrochemical preparation of synergistic nanoantimicrobials. Molecules. 2020;25:49. doi:10.3390/molecules25010049

203. Scully JR. The COVID-19 pandemic, Part 1: can antimicrobial copper-based alloys help suppress infectious transmission of viruses originating from human contact with high-touch surfaces? Corrosion. 2020;76(6):523-527. doi:10.5006/3568

204. Loeb S, Li C, Kim JH. Solar photothermal disinfection using broadband-light absorbing gold nanoparticles and carbon black. Environ Sci Technol. 2018;52:205-213. doi:10.1021/acs.est.7b04442

205. Nanografi Blog. COVID-19 and nanotechnology; 2020. Available from: https://nanografi.com/blog/covid19-and-nanotechnology/. Accessed June 15, 2021.

206. Abo-zeid Y, Ismail NSM, McLean GR, Hamdy NM. A molecular docking study repurposes FDA approved iron oxide nanoparticles to treat and control COVID-19 infection. Eur J Pharm Sci. 2020;153(153):105465. doi:10.1016/j.ejps.2020.105465

207. Dunnill CW, Parkin IP. Nitrogen-doped TiO2 thin films: photocatalytic applications for healthcare environments. Dalton Transact. 2011;40:1635-1640. doi:10.1039/C0DT00494D

208. Hasan J, Pyke A, Nair N, et al. Antiviral nanostructured surfaces reduce the viability of SARSCoV-2. ACS Biomater Sci Eng. 2020;6(9):4858-4861. doi:10.1021/acsbiomaterials.0c01091

209. Palmieri V, Papi M. Can graphene take part in the fight against COVID-19? Nano Today. 2020;33:100883. doi:10.1016/j. nantod.2020.100883 
210. Peddinti BST, Downs SN, Yan J, et al. Rapid and repetitive inactivation of SARS-CoV-2 and Human coronavirus on selfdisinfecting anionic polymers. Adv Sci. 2021;8(11):2003503. doi:10.1002/advs.202003503

211. Cavalcanti IDL, Nogueira MCBL. Pharmaceutical nanotechnology: which products are been designed against COVID-19? $J$ Nanopart Res. 2020;22(276). doi:10.1007/s11051-020-05010-6

212. Idumah CI. Influence of nanotechnology in polymeric textiles, applications, and fight against COVID-19. $J$ Text Inst. 2020:1-21. doi:10.1080/00405000.2020.1858600

213. Semple S, Cherrie JW. Covid-19: protecting worker health. Ann Work Expo Health. 2020;64(5):461-464. doi:10.1093/annweh/ wxaa033

214. Palmieria V, De maio FD, Spirito MD, Papi M. Face masks and nanotechnology: keep the blue side up. Nano Today. 2021;37:101077. doi:10.1016/j.nantod.2021.101077

215. Bhattacharjee S, Joshi R, Chughtai AA. Graphene modified multifunctional personal protective clothing. Adv Mater Interfaces. 2019;6:1900622. doi:10.1002/admi.201900622

216. Wang D, Sun B, Wang J, et al. Can masks be reused after hot water decontamination during the COVID-19 pandemic? Engineering. 2020;6:1115-1121. doi:10.1016/j.eng.2020.05.016

217. Riediker M. Nano-safety research lessons for dealing with aerosol transmissions of COVID-19. Nanotoxicology. 2020;14(6):866868. doi:10.1080/17435390.2020.1786185

218. Krajnc PA, Pirker L, Centa GU, et al. Size- and time-dependent particle removal efficiency of face masks and improvised respiratory protection equipment used during the COVID-19 pandemic. Sensors. 2021;21:1567. doi:10.3390/s21051567

219. Coté JJ, Haggstrom J, Vivekanandan R, et al. COVID-19 and a novel initiative to improve safety by $3 \mathrm{D}$ printing personal protective equipment parts from computed tomography. $3 D$ Print Med. 2020;6:20. doi:10.1186/s41205-020-00073-6

220. Ramaiah GB, Tegegne A, Melese B. Functionality of nanomaterials and its technological aspects - used in preventing, diagnosing and treating COVID-19. Mater Today. 2021. doi:10.1016/j. matpr.2021.04.306

221. Talebian S, Wallace GG, Schroeder A, Stellacci F, Conde J. Nanotechnology-based disinfectants and sensors for SARS-CoV2. Nat Nanotechnol. 2020;15:618-624. doi:10.1038/s41565-0200751-0

222. Ahmed MK, Afifi M, Uskokovi V. Protecting healthcare workers during COVID-19 pandemic with nanotechnology: a protocol for a new device from Egypt. $J$ Infect Public Health. 2020;13:12431246. doi:10.1016/j.jiph.2020.07.015

223. O'Dowd K, Nair KM, Forouzandeh P, et al. Face masks and respirators in the fight against the COVID-19 pandemic: a review of current materials, advances and future perspectives. Materials. 2020;13:3363. doi:10.3390/ma13153363

224. Khurana A, Allawadh P, Khurana I, et al. Role of nanotechnology behind the success of mRNA vaccines for COVID-19. Nano Today. 2020;38(2021):101142. doi:10.1016/j.nantod.2021.101142

225. Peek LJ, Middaugh CR, Berkland C. Nanotechnology in vaccine delivery. Adv Drug Deliv Rev. 2008;60(8):915-928. doi:10.1016/ j.addr.2007.05.017

226. Chen YC, Cheng H, Yang Y, Yeh M. Nanotechnologies Applied in Biomedical Vaccines. Intech; 2016:84-105. doi:10.5772/63453

227. Baran A. Nanotechnology: legal and ethical issues. Eng Manag Prod Serv. 2016;8(1):47-54. doi:10.1515/emj-2016-0005

228. Ridge SJ. A regulatory framework for nano technology. Naval Postgraduate School Monterey, California; 2018:1-55. Available from: https://sciendo.com/downloadpdf/journals/emj/8/1/articlep47.xml. Accessed August 5, 2021.

229. Pandey G, Jain P. Assessing the nanotechnology on the grounds of costs, benefits, and risks. Beni-Suef Univ J Basic Appl Sci. 2020;9(63). doi:10.1186/s43088-020-00085-5
230. The Royal Society and the Royal Academy of engineering. Nanosci Nanotechnol. 2004;46(2004). doi:10.1007/s00234-0041255-6

231. Fischer DB. Nanotechnology - scientific and regulatory challenges. Vill Environ L J. 2008;19(2):315.

232. Hamburg MA; Food \& Drugs Administration. FDA's approach to regulation of products of nanotechnology. Identifying nanomaterials for regulation. Science. 2012;336(6079):299-300. doi:10.1126/science. 1205441

233. WHO. Nanotechnology and human health: scientific evidence and risk governance. ISEE Conference Abstracts; Vol. 1; 2014. doi:10.1289/isee.2014.p3-821.

234. Picecchi D. Tiny things with a huge impact: the international regulation of nanomaterials. Mich J Environ Adm Law. 2018;7 (2):447-478. doi:10.5281/zenodo. 1288510

235. Orthen B. Nanotechnology: health and environmental risks of nanomaterials; 2007:1-65. Available from: www.baua.de/en/ TopicsfromAtoZ/HazardousSubstances/Nanotechnology/ Nanotechnology.html. Accessed August 5, 2021.

236. OECD International Futures Programme. Opportunities and risks of nanotechnologies. Report; 2007:46. Available from: https:// www.oecd.org/science/nanosafety/44108334.pdf. Accessed August 5, 2021.

237. Morigi V, Tocchio A, Pellegrini CB, Sakamoto JH, Arnone M, Tasciotti E. Nanotechnology in medicine: from inception to market domination. J Drug Deliv. 2012;2012:1-7. doi:10.1155/2012/389485

238. Bosetti R, Marneffe W, Vereeck L. Assessing the need of qualityadjusted cost-effectiveness studies of nanotechnological cancer therapies. Nanomedicine. 2013;8(3):487-497. doi:10.2217/nnm.13.15

239. Bosetti R, Jones SL. Cost-effectiveness of nanomedicine: estimating the real size of nano-costs. Nanomedicine. 2019;14(11):13671370. doi:10.2217/nnm-2019-0130

240. Bosetti R. Cost-effectiveness of nanomedicine: the path to a future successful and dominant market? Nanomedicine. 2015;10 (12):1851-1853. doi: $10.2217 / \mathrm{nnm} .15 .74$

241. Loubaton B. Exploring the quantitative dimensions of the economic impact of nanomedicine. European Technology Platform. (Online); 2012. Available from: https://www.nano.gov/sites/ default/files/medicine_-_loubaton.pdf. Accessed August 5, 2021.

242. Mokhtari T, Hassani F, Ghaffari N, Ebrahimi B, Yarahmadi A, Hassanzadeh G. COVID-19 and multiorgan failure: a narrative review on potential mechanisms. J Mol Histol. 2020;51(6):613628. doi:10.1007/s10735-020-09915-3

243. Shin MD, Shukla S, Chung YH, et al. COVID-19 vaccine development and a potential nanomaterial path forward. Nat Nanotechnol. 2020;15:646-655. doi:10.1038/s41565-020-0737-y

244. Cagno V, Andreozzi P, D’Alicarnasso M, et al. Broad-spectrum non-toxic antiviral nanoparticles with a virucidal inhibition mechanism. Nat Mater. 2018;17:195-203. doi:10.1038/nmat5053

245. Chauhan G, Madou MJ, Kalra S, Chopra V, Ghosh D, MartinezChapa SO. Nanotechnology for COVID-19: therapeutics and vaccine research. ACS Nano. 2020;14:7760-7782. doi:10.1021/ acsnano.0c04006

246. Malabadi RB, Meti NT, Chalannavar RK. Applications of nanotechnology in vaccine development for coronavirus (SARS-CoV2) disease (Covid-19). IJRSI. 2021;8(2):ISSN 2321-2705. doi:10.51244/IJRSI.2021.8312

247. Liu K, Gu Z, Islam S, et al. Global landscape of patents related to human coronaviruses. Int J Biol Sci. 2021;17(6):1588-1599. doi:10.7150/ijbs.58807

248. Florindo HF, Kleiner R, Vaskovich-Koubi D, et al. Immunemediated approaches against COVID-19. Nat Nanotechnol. 2020;15:630-645. doi:10.1038/s41565-020-0732-3

249. Buzea C, Pacheco I. Toxicity of nanoparticles. Nanotech Eco Efficient Const. 2019;705-754. doi:10.1016/b978-0-08-1026410.00028 
250. Hadrup N, Sharma AK, Loeschner K, et al. Pulmonary toxicity of silver vapours, nanoparticles and fine dusts: a review. Regul Toxicol Pharmacol. 2020;115:104690. doi:10.1016/j.yrtph.2020.104690

251. Nho R. Pathological effects of nano-sized particles on the respiratory system. Nanomed Nanotech Bio Med. 2020;29:102242. doi:10.1016/j.nano.2020.102242
252. Vafea MT, Atalla E, Georgakas J, et al. Emerging technologies for the study, diagnosis, and treatment of patients with COVID-19. Cell Mol Bioeng. 2020;13(4):249-257. doi:10.1007/s12195-02000629-w

\section{Publish your work in this journal}

The International Journal of Nanomedicine is an international, peerreviewed journal focusing on the application of nanotechnology in diagnostics, therapeutics, and drug delivery systems throughout the biomedical field. This journal is indexed on PubMed Central, MedLine, CAS, SciSearch ${ }^{\circledR}$, Current Contents ${ }^{\circledR} /$ Clinical Medicine, $^{\circ}$
Journal Citation Reports/Science Edition, EMBase, Scopus and the Elsevier Bibliographic databases. The manuscript management system is completely online and includes a very quick and fair peer-review system, which is all easy to use. Visit http://www.dovepress.com/ testimonials.php to read real quotes from published authors. 